\title{
Comparative Effectiveness and Safety of Monoclonal Antibodies (Bevacizumab, Cetuximab, and Panitumumab) in Combination with Chemotherapy for Metastatic Colorectal Cancer: A Systematic Review and Meta-Analysis
}

\author{
Wânia Cristina da Silva ${ }^{1}$ (1) Vânia Eloisa de Araujo ${ }^{1,2}$ - Ellias Magalhães e Abreu Lima ${ }^{3}$. \\ Jessica Barreto Ribeiro dos Santos ${ }^{1}\left[\right.$ [ $\cdot$ Michael Ruberson Ribeiro da Silva ${ }^{1}[$.

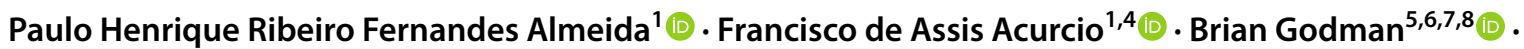 \\ Amanj Kurdi ${ }^{5,9}$ ( Mariângela Leal Cherchiglia ${ }^{1,4} \oplus$ Eli lola Gurgel Andrade ${ }^{1,4}(\mathbb{D}$
}

Published online: 30 November 2018

(c) The Author(s) 2018

\begin{abstract}
Background The last decade has seen the increasing use of biological medicines in combination with chemotherapy containing 5-fluorouracil/oxaliplatin or irinotecan for the treatment of metastatic colorectal cancer (mCRC). These combinations have resulted in increased progression-free survival (PFS) in patients with $\mathrm{mCRC}$; however, there are remaining concerns over the extent of their effect on overall survival (OS). Published studies to date suggest no major differences between the three currently available monoclonal antibodies (MoAbs); however, there are differences in costs. In addition, there is rising litigation in Brazil in order to access these medicines as they are currently not reimbursed.

Objective The aim was to investigate the comparative effectiveness and safety of three MoAbs (bevacizumab, cetuximab and panitumumab) associated with fluoropyrimidine-based chemotherapy regimens and compared to fluoropyrimidine-based chemotherapy alone in patients with $\mathrm{mCRC}$, through an updated systematic review and meta-analysis of concurrent or nonconcurrent observational cohort studies, to guide authorities and the judiciary.

Method A systematic review and meta-analysis was performed based on cohort studies published in databases up to November 2017. Effectiveness measures included OS, PFS, post-progression survival (PPS), Response Evaluation Criteria In Solid Tumors (RECIST), response rate, metastasectomy and safety. The methodological quality of the studies was also evaluated. Results A total of 21 observational cohort studies were included. There were statistically significant and clinically relevant benefits in patients treated with bevacizumab versus no bevacizumab mainly around OS, PFS, PPS and the metastasectomy rate, but not for the disease control rates. However, there was an increase in treatment-related toxicities and concerns with the heterogeneity of the studies.

Conclusion The results pointed to an advantage in favor of bevacizumab for OS, PFS, PPS, and metastasectomy. Although this advantage may be considered clinically modest, bevacizumab represents a hope for increased survival and a chance of metastasectomy for patients with mCRC. However, there are serious adverse events associated with its use, especially severe hypertension and gastrointestinal perforation, that need to be considered.
\end{abstract}

Electronic supplementary material The online version of this article (https://doi.org/10.1007/s40259-018-0322-1) contains supplementary material, which is available to authorized users.

Brian Godman

Brian.Godman@strath.ac.uk; Brian.Godman@ki.se;

Brian.Godman@liverpool.ac.uk

Extended author information available on the last page of the article 


\section{Key Points}

The use of monoclonal antibodies (MoAbs) as a therapeutic option for metastatic colorectal cancer (mCRC) created expectations for greater overall survival as well as decreased toxicity and grade $\geq 3$ adverse event complications compared with cytotoxic chemotherapy.

The results of the studies included in this meta-analysis showed increased overall survival, progression-free survival and metastasectomy rate in patients with $\mathrm{mCRC}$ using MoAbs; however, there was great heterogeneity in the studies and severe adverse events.

It is important to assess the value and cost of interventions for both first- and second-line treatments when making choices. Marginal gains with associated high costs are difficult to justify within universal healthcare systems.

\section{Introduction}

Cancer is one of the leading causes of death worldwide, with more than 8.8 million deaths in 2015, up from 8.2 million deaths in 2012 [1, 2], with breast, colorectal, lung, and stomach cancers the most commonly diagnosed cancers. The overall economic burden of cancer was estimated at US\$1.6 trillion in 2010 and rising [2]. Colorectal cancer (CRC) continues to be a worldwide public health problem, with the number of new cases per year of CRC in 2012 at 1.36 million $[3,4]$, corresponding to $10 \%$ of patients diagnosed with cancer in 2012. Overall, CRC is the third most common neoplasm in men and the second most common in women [5], with 694,000 deaths in 2012 [3].

CRC is a curable disease if diagnosed in early stages [6]. However, between 70 and $90 \%$ of CRC cases are currently diagnosed in advanced stages of the disease, resulting in initiatives including biomarkers to help identify patients earlier [5-8].

Since the 1990 s, fluoropyrimidine-based chemotherapy (CT) (5-fluorouracil [5-FU] or capecitabine) has been the principal treatment for $\mathrm{CRC}$, with demonstrated benefits in overall survival (OS) $[9,10]$. Irinotecan and oxaliplatin are widely used in combination with 5-FU and leucovorin (folinic acid) as first- or second-line treatment for metastatic CRC (mCRC) [11, 12], with studies demonstrating their addition as first-line treatment improves median survival by $2-4$ months $[9,11]$. Whilst $5-\mathrm{FU}$ and oxaliplatin have improved survival rates, this combination has resulted in a higher incidence of severe adverse events, however, with acceptable tolerability and maintenance of quality of life [11].

The use of molecular biological agents, monoclonal antibodies (MoAbs), in combination with 5-FU/oxaliplatin or irinotecan has become widespread to try and improve survival rates in patients with $\mathrm{mCRC}[6,12-15]$. However, the biological medicines have appreciably increased the cost of medicines with the high costs of MoAbs, often with limited health gain versus current standards. The high cost of biological medicines coupled with growing cancer prevalence rates have resulted in concerns for the future sustainability of healthcare systems [16-23].

The MoAbs used to treat patients with mCRC include cetuximab (CETUX) and panitumumab (PANIT) [5, 14], which act on the epidermal growth factor receptor (EGFR), and bevacizumab (BEVA) [5], which acts on the vascular endothelial growth factor (VEGF) [5, 24]. They have all improved progression-free survival (PFS) in patients with mCRC; however, there have been concerns expressed regarding the extent of their effectiveness with improving OS [14] and their cost-effectiveness [25, 26]. Theoretically, payers of healthcare should not grant high prices for new cancer medicines that improve PFS but have limited or no improvement on OS, as this will affect available resources for other high-priority disease areas [27]. However, this has to be balanced against the emotive nature of the disease and the anxiety that patients with cancer have [28].

Improved targeting of high-priced biological medicines could potentially address these concerns. According to Rougier and Mitry [10], MoAbs are restricted to patients without the Kirsten rat sarcoma viral oncogene (KRAS) and N-RAS oncogene mutations [29, 30]. Overall, approximately $45 \%$ of patients with mCRC with wild-type KRAS are resistant to treatment with CETUX [31]. Consequently, KRAS testing before CETUX can conserve resources [32-34].

The National Institute for Health and Care Excellence (NICE) in the UK currently recommends the use of CETUX and PANIT as an option for previously untreated anti-EGFR wild-type metastatic RAS in association with FOLFOX (folinic acid, 5-FU, oxaliplatin) or FOLFIRI (folinic acid, 5-FU, irinotecan). BEVA is currently not recommended for use in the UK, either in combination with intravenous 5-FU/folinic acid or with FOLFIRI for first-line treatment of patients with metastatic carcinoma of the colon or rectum [35-37]. Australia's Pharmaceutical Benefits Scheme does not mention BEVA for mCRC; however, it is indicated for epithelial ovarian, fallopian tube or primary peritoneal cancer [38, 39]. CETUX in combination with FOLFIRI has been approved by the Canadian Agency for Drugs and Technologies in Health for first-line treatment in patients with $\mathrm{mCRC}$ and KRAS wild-type (KRAS-WT) oncogenes [40]. NICE do not recommend CETUX (monotherapy or combination CT), 
BEVA (in combination with non-oxaliplatin CT) and PANIT (monotherapy) for mCRC after first-line CT [41].

However, BEVA was considered by the Avastin ${ }^{\circledR}$ Registry-Investigation of Effectiveness and Safety (ARIES) observational cohort study as a potential treatment for the $\mathrm{mCRC}$ in recent years [42].

A number of meta-analyses and other studies have shown no difference in health gain between these three MoAbs in mCRC patients [41-43]. Three systematic reviews, Hapani et al. [43], Lv et al. [44], and Rosa et al. [45], have also shown no additional clinical benefit with BEVA compared with CT, i.e., FOLFORI or FOLFOX, or BEVA with CETUX or PANIT, in terms of increased efficacy or reduced side effects. However, a sub-study by Hurwitz et al. [46] confirmed the effectiveness of BEVA in the KRAS-WT subgroup of mCRC patients. This compares with the meta-analysis of Wagner et al. [47], who evaluated five randomized clinical trials (RCTs) with 3101 participants comparing BEVA versus no BEVA for first-line CT, which showed significant benefits for OS or PFS in favor of BEVA-treated patients. We note though that in the no BEVA group, in addition to $\mathrm{CT}$ regimens, the authors included vatalanib (another VEGF inhibitor), which was not included in our review. In addition, there was a high incidence of grade 3 and 4 adverse events including hypertension, arterial thromboembolic events and gastrointestinal perforations in patients treated with BEVA [43, 47].

Currently, in the Brazilian health system (Sistema Único de Saúde [SUS]), BEVA, CETUX and PANIT can only be used and funded after successful litigation against the state, or $100 \%$ co-payment, since they are not incorporated into the health system. The Brazilian Health Technology Assessment Agency of SUS (Comissão Nacional de Incorporação de Tecnologias no SUS [CONITEC]) did not recommend the incorporation of CETUX for the management of mCRC in view of concerns with its price and limited health gain, and currently, BEVA and PANIT have not yet been evaluated for inclusion into SUS [48]. In view of this, successful litigation is the only means for patients to have these treatments funded within SUS. In the state of Minas Gerais (MG), public expenditure on BEVA, CETUX and PANIT as a result of successful litigation was approximately US\$20 million between 2009 and 2016 (Fig. 1E in the electronic supplementary material). This is a concern as these monies are not available for cost-effective medicines in other high-priority disease areas. Currently, the ex-factory monthly treatment costs based on prices from Câmara de Regulação do Mercado de Medicamentos (CMED) Agência Nacional de Vigilância Sanitária (ANVISA) [49] are BEVA U\$2897.90, CETUX US\$6585.10 and PANIT US\$3100.20. Consequently, CETUX is more expensive than BEVA by $127 \%$ and more expensive than PANIT by $112 \%$. PANIT is more expensive than BEVA by $6 \%$.
Faced with the contradictory scenario regarding the use of MoAbs in mCRC, as well as considerable differences in prices between these three and versus standard CT, the objective of this study was to evaluate the effectiveness and safety of BEVA, CETUX and PANIT in combination with or compared to fluoropyrimidine-based CT alone in patients with mCRC, through an updated systematic review and meta-analysis with prospective or retrospective observational cohort studies. We believe the updated review will help people better understand the benefits and harms of the different treatments in heterogeneous populations in the 'real world,' reflecting conditions in routine clinical practice [50, 51]. This is important given the increasing costs of treatments for cancer, increasing pressure on available resources $[26,27,34,52-54]$, and the extent of current litigation surrounding these three MoAbs in Brazil.

\section{Methods}

This systematic review was based on the recommendations of the guidelines for Meta-analysis Of Observational Studies in Epidemiology (MOOSE) [55], with the protocol registered with the International Prospective Register of Systematic Reviews (PROSPERO) under no. CRD42016046613 (http://www.crd.york.ac.uk/PROSPERO).

\subsection{Database and Search Strategy}

The databases searched for potentially eligible studies included MEDLINE/PubMed (Medical Literature Analysis and Retrieval System Online), LILACS (Latin American and Caribbean Health Science Literature), Cochrane Library, and EMBASE. All sources were searched until November 2017. We used various combinations of MeSH terms, including those relating to the disease, interventions, and study types (see the electronic supplementary material, Table 1E). We supplemented this search with a manual search. In the manual search, we reviewed references in the annals of the Annual Meeting of the American Society of Clinical Oncology and the European Society for Medical Oncology between January 2014 and November 2017. In addition, we also manually searched the Journal of Clinical Oncology, the British Journal of Cancer, the Journal of the American Medical Association, and the World Journal of Gastroenterology, also for the period January 2014-November 2017.

We also searched the grey literature registered in the data bank of the Brazilian Digital Library of Theses and Dissertations, the Digital Library of Theses and Dissertations of the University of São Paulo (USP), the Capes Theses Database, and the ProQuest Dissertation and Theses Database, which included academic, government and conferences 
publications, books and reports, and the Digital Library of Theses of the Federal University of Minas Gerais (UFMG).

\subsection{Selection of Studies and Eligibility Criteria}

We selected concurrent and non-concurrent observational studies of patients with mCRC. The studies compared the effectiveness and/or safety of BEVA, CETUX, and PANIT combined with FOLFIRI, FOLFOX, or fluorouracil, leucovorin and oxaliplatin (FLOX), or fluorouracil and leucovorin (5-FU/LV), or other combinations of fluoropyrimidine-based CT versus BEVA, CETUX, and PANIT, or any CT scheme including fluoropyrimidine-based CT alone in patients undergoing treatment.

The inclusion criteria included studies published in Portuguese, English or Spanish; patients aged 18 years and older of both sexes; stage IV mCRC; life expectancy > 3 months; and wild-type or mutant KRAS.

Studies were excluded if they compared doses, intervention methods, or clinical protocols; were reviews, case reports, or studies in animals; were in vitro, pharmacodynamic and/or pharmacokinetic studies; were genetic and/or genomic studies; investigated other types of cancer; assessed concomitant therapies with MoAbs other than BEVA, CETUX, and PANIT; and included participants under the age of 18 years, or those who had less than 3-months of follow-up.

\subsection{Selection of Studies and Data Collection}

The studies found in the electronic databases were collected into a single database (EndNote ${ }^{\circledR}$ software) in order to delete duplicates. The selection and inclusion of studies were performed in two stages by two pairs of independent reviewers (WS and PA, JS and MS). This included the analysis of titles/abstracts followed by the full texts. Disagreements were resolved by a third reviewer (VA). The characteristics of the patients, their treatment length, as well as effectiveness and safety data were retrieved and incorporated into an Excel spreadsheet designed for this purpose and previously tested.

\subsection{Assessment of Methodological Quality of Included Studies}

We used the Newcastle-Ottawa scale to assess the methodological quality of the observational studies $[55,56]$. In this scale, each study is assessed in three dimensions: selection of the study groups; comparability of groups; and the calculation of any exposure or outcomes of interest. The total score can be up to nine stars, and studies with a score above six are considered to be of high quality.
The sources of funding for the identified studies were examined for potential sources of bias. This is because the influence of this on subsequent findings has been seen in previously conducted reviews [57-59]. Comments regarding any conflicts of interest (COI), the source of financing of the study, including whether funded by the manufacturer of any of the evaluated MoAbs, or whether any of the authors were related to the pharmaceutical industry, or received fees, were examined and documented. The possibility of publication bias was assessed using funnel plots [60] for the outcome if more than ten studies were involved.

\subsection{Outcome Measures}

The primary outcome measures considered were OS, PFS, and post-progression survival (PPS). The assessment of OS, measured by the time between diagnosis and death from any cause, is the most accepted method to assess the outcomes of cancer treatments, especially among payers of healthcare working with finite budgets in view of concerns linking PFS and other surrogate markers with OS in solid tumors [4, 24, 61-66]. American and European oncology groups also agree that OS should be the principal outcome measure in clinical studies [4, 62, 64], although PFS is also mentioned.

It is worth noting that PFS is used as a measure to assess a direct treatment effect on patients with metastatic cancer. However, PFS can be a concern when replacing OS, especially for funding decisions based on OS estimations in, for instance, cost/quality-adjusted life year calculations [67]. Having said this, PFS is validated and relevant to the patients. However, when used alone, it is not considered to be enough evidence of benefit to patients, which is exemplified by recent guidance from the American Society of Clinical Oncology [64]. For this reason, OS is recommended as a measure of effectiveness for new cancer medicines [65, 68], with a significant effect on OS necessarily entailing a significant effect on PFS [66].

The secondary outcome measures were metastasectomy rates, response rates or disease control rate assessed by the Response Evaluation Criteria In Solid Tumors (RECIST) [69], and the occurrence of severe adverse events, considering only grade $\geq 3$. The documentation of adverse events followed the Common Terminology Criteria for Adverse Events (CTCAE, version 4.0) of the National Institutes of Health (NIH) National Cancer Institute [70]. This describes and reports adverse events in a systematic way, providing a scale of severity for each adverse event ranging from grade 1 up to grade 5, i.e., $1=$ mild; $2=$ moderate; $3=$ severe; $4=$ extremely severe, life threatening; and $5=$ death due to adverse events. 


\subsection{Summary of Data and Statistical Analysis}

The data from the studies were combined using the random effects model of the Review Manager ${ }^{\circledR}$ software, version 5.3. The results were presented by mean difference (MD) in months for continuous variables and expressed as relative risk for dichotomous variables, with a $95 \%$ confidence interval (CI). To estimate the magnitude of statistical inconsistency, we used the test $I^{2}>50 \%$ and a $p$ value of $<0.10$ in the Chi-square test. Values above $75 \%$ were considered to have high heterogeneity [60]. A sensitivity analysis was conducted to assess the causes of heterogeneity, excluding one study at a time [60] and observing the changes in the $I^{2}$ and $p$ values.

Due to the great variety of CT regimens based on fluoropyrimidines, we chose to construct the grouping of the forest graph by the similarity of the treatments.

In cases where it was not possible to carry out the metaanalysis, a qualitative synthesis of the studies was performed as the heterogeneity of the measurement instruments and the data did not allow for quantitative synthesis.

\section{Results}

\subsection{Search Results and Included Studies}

We found a total of 2363 publications in the electronic databases. After excluding duplicates, 2175 articles were selected for analysis of the titles and abstracts, and 269 for thorough reading. After a full analysis of the articles, 21 studies were finally included in the meta-analysis (see the electronic supplementary material, Fig. 2E).

\subsection{General Characteristics of the Studies Included in the Meta-Analysis}

The 21 observational studies that were included in the metaanalysis were of the cohort type. Seventeen of them had a non-concurrent design and four a concurrent design. The follow-up time ranged from 6 to 37 months; however, this information was not reported in eight studies [69-76]. The duration of the studies ranged from 36 months ( 3 years) to 132 months (11 years); however, no information was given in two studies $[78,79]$. Eight studies declared COI, nine studies declared having no COI, and three studies did not provide this information. With respect to funding, seven studies did not mention the sources of funding [71, 72, 76, 80-83], seven declared having been funded by the pharmaceutical industry $[42,73,75,78,84-86]$, and the other studies were funded through other sources.

Nine studies assessed treatment with BEVA versus various CT regimens including fluoropyrimidine-based CT (i.e., including FOLFIRI, FOLFOX, and FLOX), four studies assessed BEVA versus CETUX, and only two studies compared CETUX versus PANIT. Five studies assessed treatment with BEVA during maintenance therapy, i.e., no BEVA beyond disease progression (no BBP) (BEVA vs no BBP) (Table 1).

\subsection{Methodological Quality}

Among the studies assessed for methodological quality, two studies [42, 84] obtained the maximum score of nine stars using the Newcastle-Ottawa scale, three scored eight stars, seven scored seven stars, eight studies scored six, and one study scored five stars. As a result, the studies were seen overall as of moderate quality (Table 1). There was, though, asymmetry in the funnel plot for OS, suggesting publication bias (see the electronic supplementary material, Figs. 3E and 4E).

\subsection{Clinical Characteristics of the Patients in the Included Studies}

To assess the comparative effectiveness and safety of the MoAbs (BEVA, CETUX, and PANIT) combined with CT or compared to only CT schemes, 10,180 participants were assessed in the 21 studies. The size of the studies ranged between 26 and 2526 patients.

With respect to the sociodemographic and clinical characteristics of the patients in the studies, the patients' mean ages ranged between 47 and 73 years and $40.5 \%$ were women. On average, according to data from five studies, $54 \%$ of the patients had exhibited wild-type KRAS and $45 \%$ unknown KRAS. In 14 of the studies, the primary location of the tumor was in the colon versus the rectum or other sites, and this was seen in $75 \%$ of patients. For lymph nodal metastases, only four studies presented data, and these metastases occurred in $32 \%$ of patients. According to data collected from six studies, the proportion of liver and lung metastases was $56 \%$ and $29 \%$, respectively. Seven studies presented data for primary tumor removal, with $72.5 \%$ of the patients having undergone resection of their primary tumor. Regarding the rate of disease control, five studies showed a $74 \%$ control rate, whereas, for progressive disease, this was $27 \%$ of patients according to the RECIST scale (Table 2).

\subsection{Summary of the Data}

BEVA was the most used MoAb in the largest number of studies that met the inclusion criteria. Due to the scarcity of comparative observational studies for PANIT and CETUX, we organized a comparison with a group called 'with BEVA' versus other therapeutic schemes that did not contain BEVA (no BEVA). From this group, we obtained five intervention 


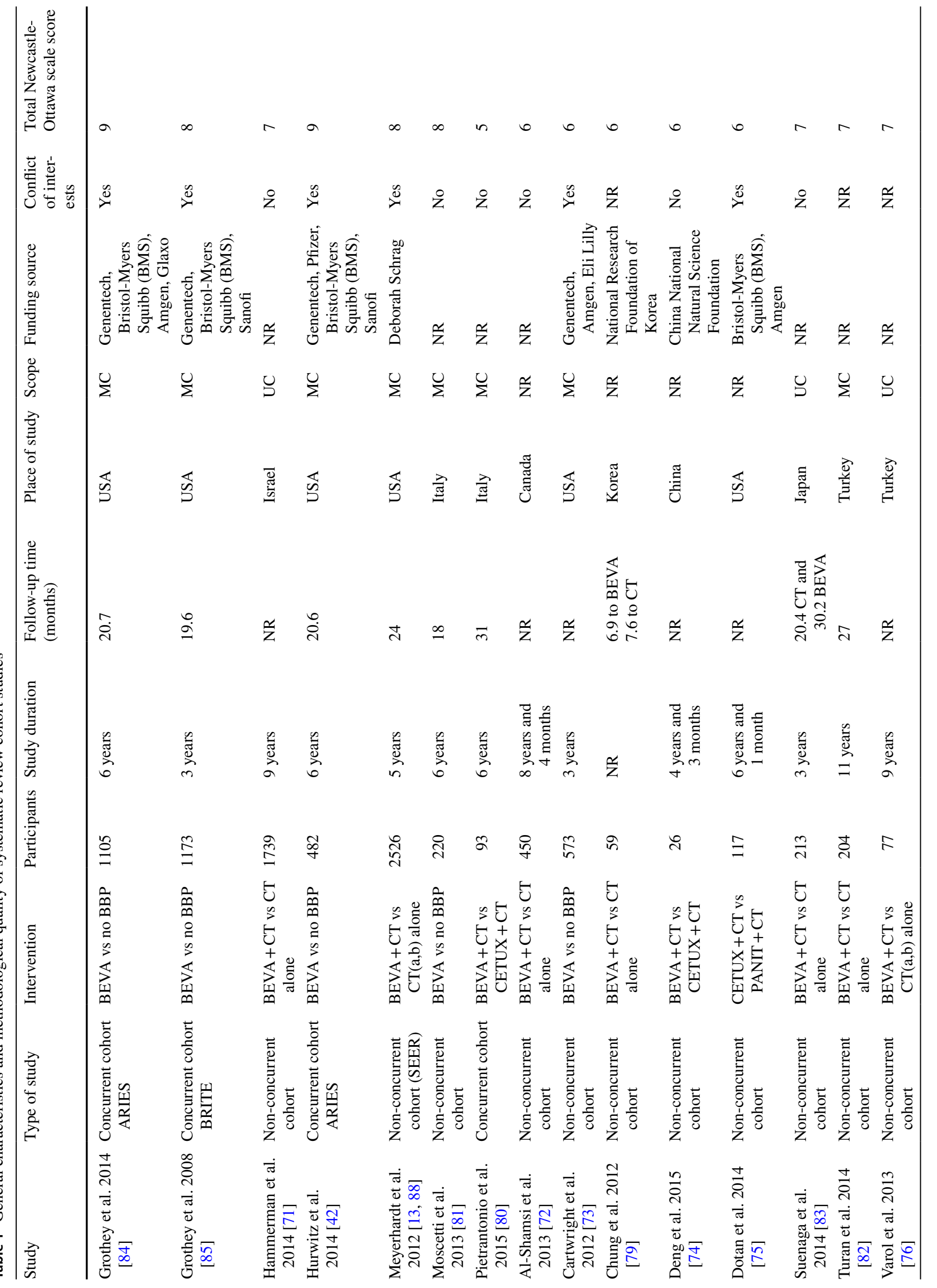




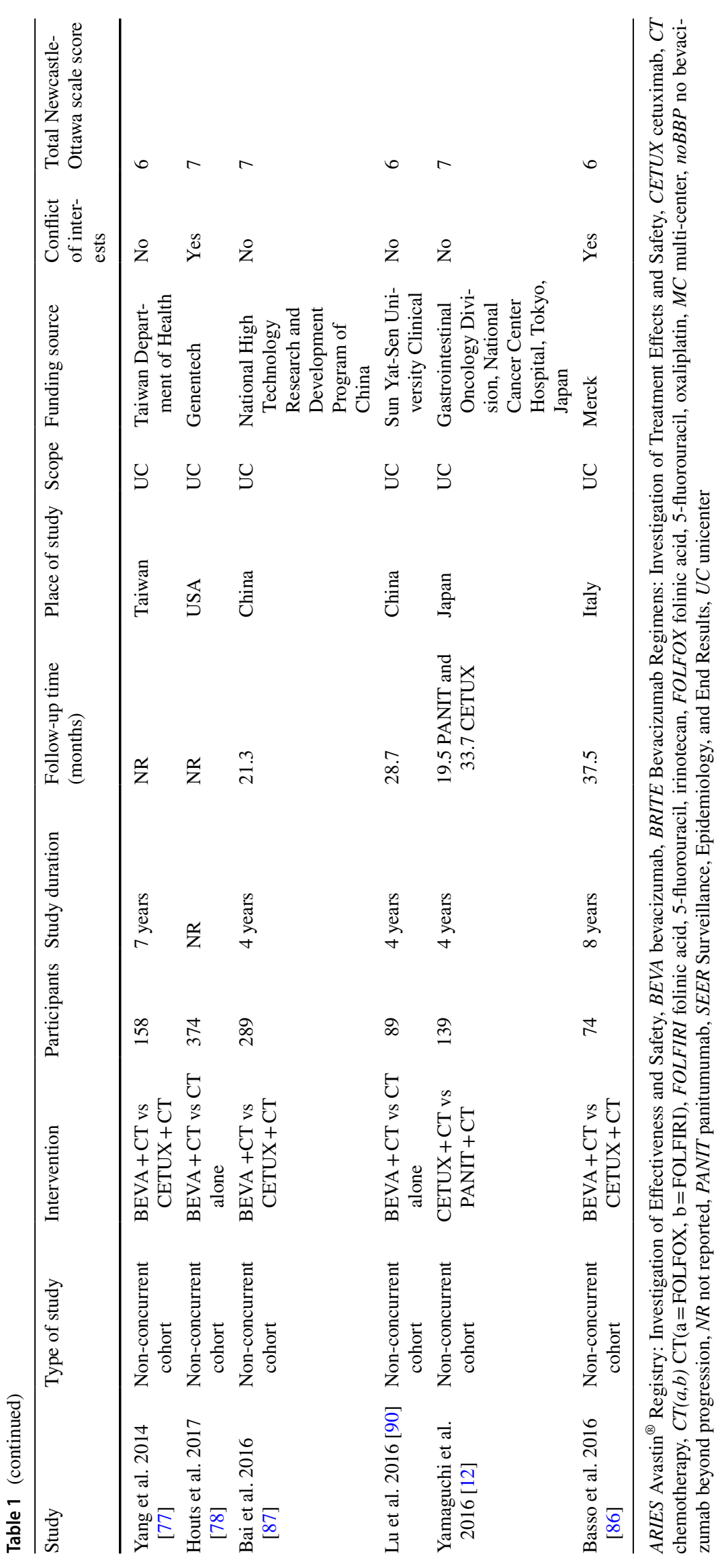




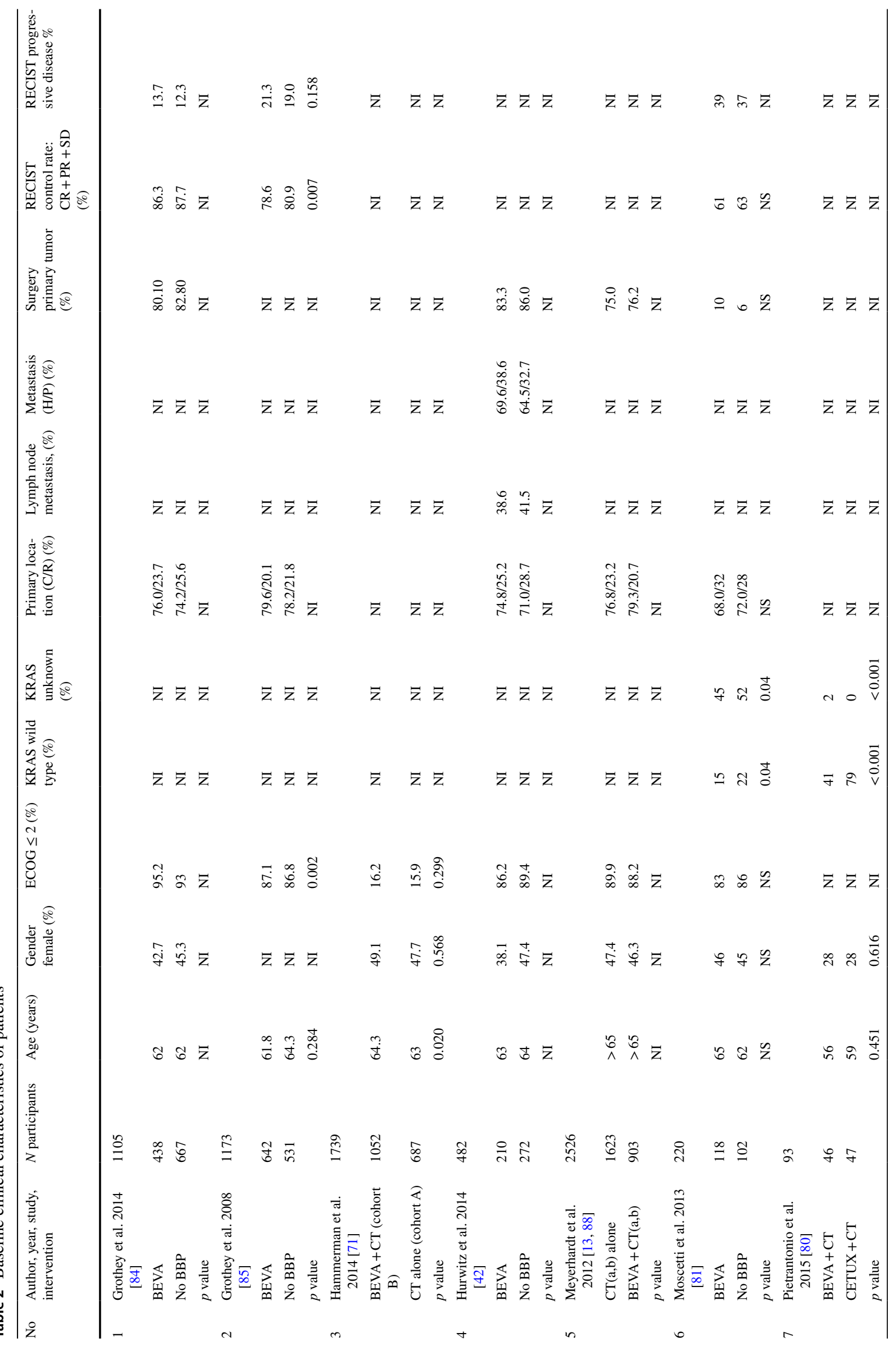




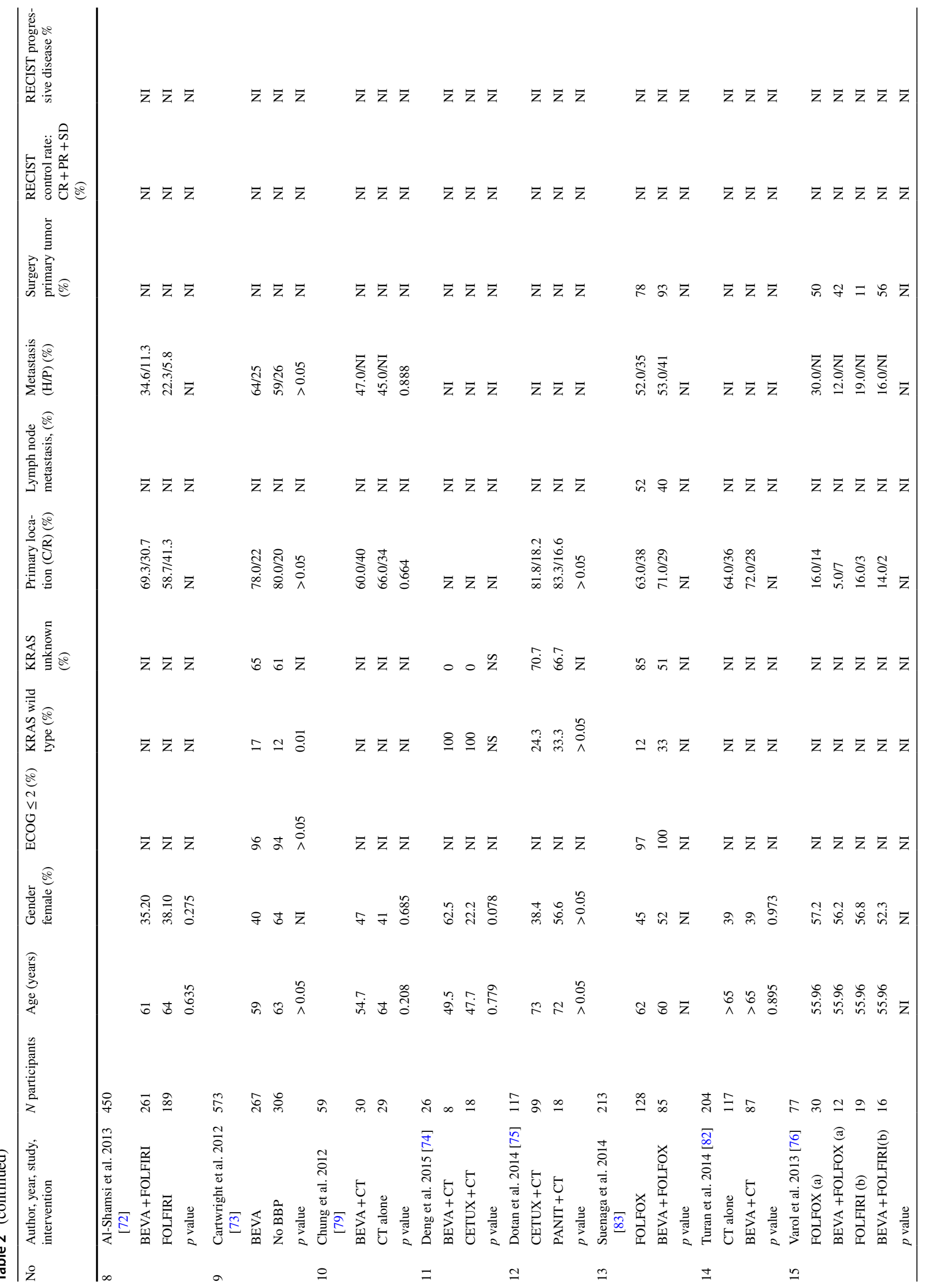




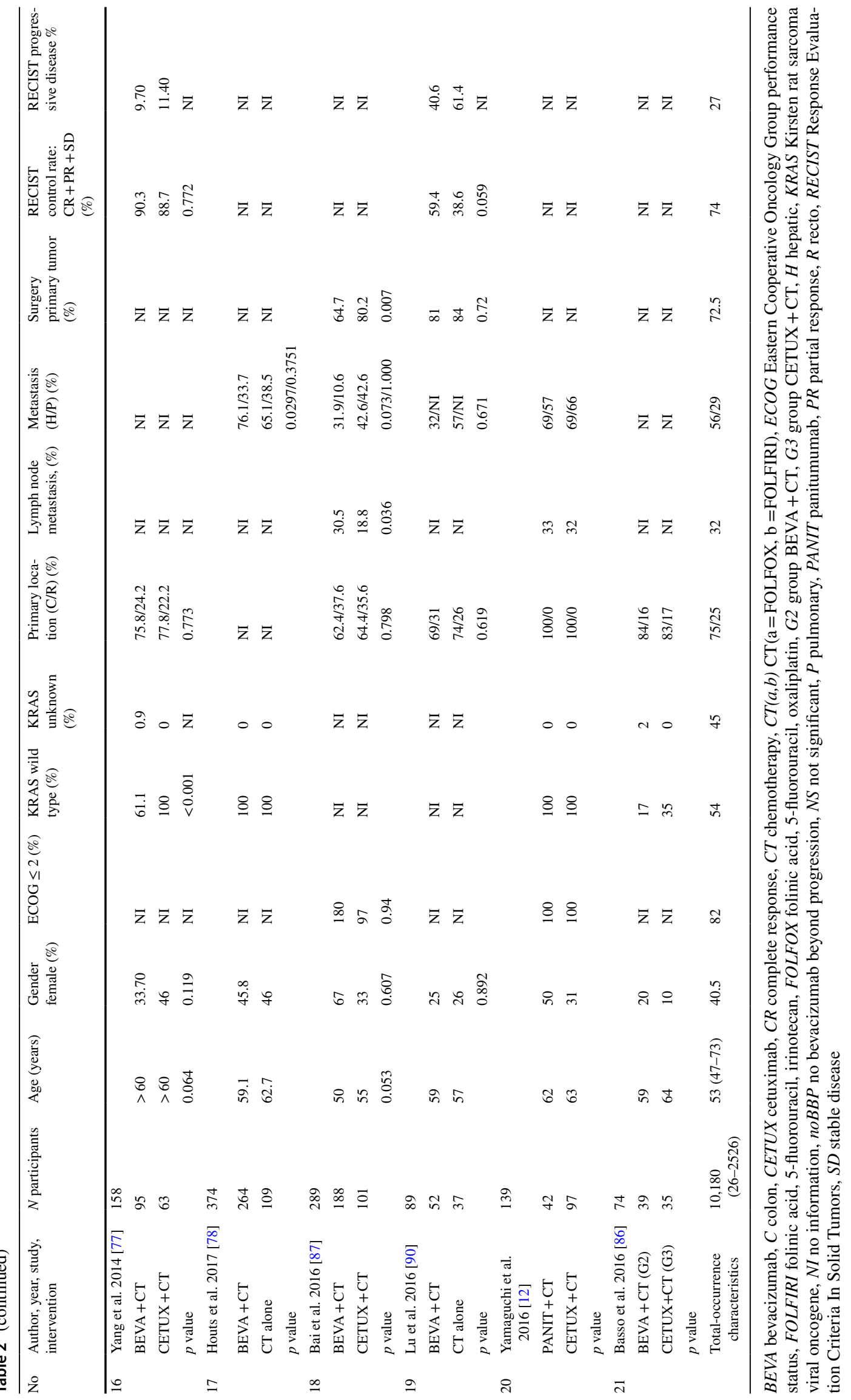


subgroups (Table 3), namely (a) BEVA + CT versus $\mathrm{CT}$ alone without specification of the combination; (b) BEVA + FOLFIRI versus FOLFIRI; (c) BEVA + FOLFOX versus FOLFOX; (d) BEVA + CT versus CETUX + CT; and (e) BEVA versus no BBP (without BEVA maintenance beyond progression and maintenance of some CT scheme). Two arms were built, i.e., BEVA versus no BEVA, since it was not possible to compare CETUX versus PANIT since there were concerns with the key measurements used. In addition to finding only two studies $[12,75]$ with this comparison, the authors used the median as a measure of central tendency. This is different from the other arms, where means were used for comparative purposes, making it difficult to include this arm in the analysis.

\subsection{Primary Outcomes}

OS and PFS had been assessed in all the intervention subgroups described, and PPS had been assessed in only one intervention subgroup (BEVA vs no BBP) $[42,73,81,84$, 85].

\subsubsection{Overall Survival}

We included 16 studies on OS, with 11,094 participants. There were significant differences between the groups BEVA versus no BEVA [13, 42, 71, 73, 74, 77, 78, 81-87]
$\left(\mathrm{MD}=4.07 ; 95 \%\right.$ CI $\left.1.69-6.45 ; p<0.001 ; I^{2}=81 \%\right)$. However, when we look at the clusters of CT regimens separately, we note the following: there were no statistically significant differences between the subgroups of BEVA $+\mathrm{CT}$ versus $\mathrm{CT}$ alone $[13,71,78,82](\mathrm{MD}=2.83 ; 95 \% \mathrm{CI}-1.76$ to 7.41 ; $\left.p=0.23 ; I^{2}=87 \%\right) ; \mathrm{BEVA}+\mathrm{CT}$ versus CETUX + CT $[74$, $77,86,87](\mathrm{MD}=-0.52 ; 95 \% \mathrm{CI}-7.7$ to $6.67 ; p=0.89$; $\left.I^{2}=0 \%\right)$ and BEVA + FOLFOX versus FOLFOX $[13,83]$ $\left(\mathrm{MD}=8.63 ; 95 \% \mathrm{CI}-9.93\right.$ to $\left.27.19 ; p=0.36 ; I^{2}=96 \%\right)$.

The subgroup BEVA+FOLFORI versus FOLFIRI [13] had been assessed in only one study, and the OS difference was not significant. The only significant differences were in the subgroups BEVA versus no BBP [42, 73, 81, 83, 85] $\left(\mathrm{MD}=4.89 ; 95 \%\right.$ CI $\left.1.91-7.87 ; I^{2}=73 \%\right)$, favoring BEVA (Table 3; Fig. 1).

We performed heterogeneity tests taking into consideration the grouping of the CT regimens (or FOLFIRI or FOLFOX). We noticed that there was a difference when we removed the studies that used FOLFOX in association with BEVA. The heterogeneity was reduced from $I^{2}=81 \%$ to $I^{2}=68 \%$. The withdrawal of the two studies (Suenaga et al. [83] and Meyerhardt et al. [13]) using FOLFOX as the associated $\mathrm{CT}$ in the comparison arms with BEVA reduced the heterogeneity; however, this did not significantly change the outcome of this meta-analysis.

When we undertook sensitivity analysis with the exclusion of the study by Grothey et al. [85], in the BEVA versus

Table 3 Outcomes evaluated in the meta-analysis: BEVA vs schemes without BEVA (no BEVA)

\begin{tabular}{|c|c|c|c|c|c|}
\hline Outcomes & Studies $n$ (references) & Participants & Estimated effect $[95 \% \mathrm{CI}]$ ( $p$ value) & $I^{2}(\%)$ & $p$ value \\
\hline Overall survival (months) & $16[13,42,71,73,74,77,78,81-87]$ & 11,094 & $4.07[1.69$ to 6.45$](p<0.001)$ & 81 & 0.00001 \\
\hline $\mathrm{BEVA}+\mathrm{CT}$ vs $\mathrm{CT}$ alone & $4[13,71,78,82]$ & 4842 & $2.83[-1.76$ to 7.41$](p=0.23)$ & 87 & 0.00001 \\
\hline BEVA + FOLFIRI vs FOLFIRI & $1[13]$ & 267 & $2.20[-4.43$ to 8.83$](p=0.52)$ & NA & NA \\
\hline BEVA + FOLFOX vs FOLFOX & $2[13,83]$ & 1885 & $8.63[-9.93$ to 27.19$](p=0.36)$ & 96 & 0.00001 \\
\hline $\mathrm{BEVA}+\mathrm{CT}$ vs CETUX $+\mathrm{CT}$ & $4[74,77,86,87]$ & 547 & $-0.52[-7.71$ to 6.67$](p=0.89)$ & 0 & 0.99 \\
\hline BEVA vs no BBP & $5[42,73,81,84,85]$ & 3553 & $4.89[1.91$ to 7.87$](p=0.001)$ & 73 & 0.005 \\
\hline $\begin{array}{l}\text { Progression-free survival } \\
\text { (months) }\end{array}$ & $11[42,71,74,76,78,81-83,87,88]$ & 3704 & $2.85[0.74$ to 4.96$](p<0.008)$ & 90 & 0.00001 \\
\hline $\mathrm{BEVA}+\mathrm{CT}$ vs $\mathrm{CT}$ alone & $4[71,78,82,88]$ & 2405 & $2.21[-0.06$ to 4.48$](p=0.06)$ & 70 & 0.002 \\
\hline BEVA + FOLFORI vs FOLFIRI & $1[76]$ & 35 & $8.60[7.52$ to 9.68$](p<0.00001)$ & NA & NA \\
\hline BEVA + FOLFOX vs FOLFOX & $2[76,83]$ & 247 & $3.72[-1.53$ to 8.96$](p=0.16)$ & 95 & 0.0001 \\
\hline $\mathrm{BEVA}+\mathrm{CT}$ vs CETUX + CT & $2[74,87]$ & 315 & $2.00[0.33$ to 3.67$](p=0.04)$ & 0 & 0.67 \\
\hline BEVA vs no BBP & $2[42,81]$ & 702 & $1.65[-3.74$ to 7.03$](p=0.55)$ & 92 & 0.0003 \\
\hline $\begin{array}{l}\text { Post-progression survival } \\
\text { (months) }\end{array}$ & $3[73,84,85]$ & 2851 & $5.90[2.59$ to 9.21$](p=0.0005)$ & 82 & 0.004 \\
\hline BEVA vs no BBP & $3[73,84,85]$ & 2851 & $5.90[2.59$ to 9.21$](p=0.0005)$ & 82 & 0.004 \\
\hline Disease control rate (RECIST) & $5[74,77,80,83,88]$ & 571 & $1.05[0.98$ to 1.12$](p=0.45)$ & 10 & 0.18 \\
\hline Metastasectomy rate (\%) & $2[71,77]$ & 1897 & $2.01[1.44$ to 2.81$](p<0.0001)$ & 0 & 0.87 \\
\hline
\end{tabular}

$I^{2}>50 \%$ and a $p$ value of the Chi-square test $<0.10$ indicate significant heterogeneity between the studies

BEVA bevacizumab, CETUX cetuximab, CI confidence interval, CT chemotherapy, FOLFIRI folinic acid, 5-fluorouracil, irinotecan, FOLFOX folinic acid, 5-fluorouracil, oxaliplatin, $I^{2}$ heterogeneity, NA not applicable, no BBP no bevacizumab beyond progression, RECIST Response Evaluation Criteria In Solid Tumors 


\begin{tabular}{|c|c|c|c|c|c|c|c|c|c|c|c|c|}
\hline \multirow[b]{2}{*}{ Study or Subgroup } & \multicolumn{3}{|c|}{ BEVA } & \multicolumn{3}{|c|}{ noBEVA } & \multirow{2}{*}{\multicolumn{2}{|c|}{$\begin{array}{l}\text { Mean Difference } \\
\text { IV, Random, } 95 \% \mathrm{Cl}\end{array}$}} & \multirow{2}{*}{\multicolumn{4}{|c|}{$\begin{array}{c}\text { Mean Difference } \\
\text { IV, Random, } 95 \% \mathrm{CI}\end{array}$}} \\
\hline & Mean & SD & Total & Mean & SD & Total & & & & & & \\
\hline \multicolumn{9}{|c|}{ 1.1.1 a) BEVA + CT vs CT alone } & & & \multirow{5}{*}{$\rightarrow$} & \\
\hline Hammerman 2015 [71] & 23 & 21.4883 & 1052 & 15 & 21.3591 & 687 & $9.8 \%$ & $8.00[5.94,10.06]$ & & & & \\
\hline Houts 2017 [78] & 26.91 & 21.5373 & 264 & 23.33 & 19.1196 & 109 & $7.7 \%$ & $3.58[-0.85,8.01]$ & & & & \\
\hline Meyerhardt 2012 [13] & 19.2 & 19.9047 & 903 & 16.5 & 34.9169 & 1623 & $9.7 \%$ & $2.70[0.56,4.84]$ & & & & \\
\hline $\begin{array}{l}\text { Turan } 2012[82] \\
\text { Subtotal }(95 \% \mathrm{Cl})\end{array}$ & 42.95 & 30.7326 & $\begin{array}{r}87 \\
2306\end{array}$ & 53.95 & 42.8707 & $\begin{array}{r}117 \\
2536\end{array}$ & $\begin{array}{r}3.6 \% \\
30.9 \%\end{array}$ & $\begin{array}{r}-11.00[-21.10,-0.90] \\
2.83[-1.76,7.41]\end{array}$ & & & & \\
\hline \multicolumn{12}{|c|}{$\begin{array}{l}\text { Heterogeneity: } \mathrm{Tau}^{2}=16.52 ; \mathrm{Chi}^{2}=22.63, \mathrm{df}=3(\mathrm{P}<0.0001) ; \mathrm{I}^{2}=87 \% \\
\text { Test for overall effect: } Z=1.21(\mathrm{P}=0.23)\end{array}$} & \\
\hline \multicolumn{12}{|c|}{ 1.1.2 b) BEVA + FOLFIRI vs FOLFIRI } & \\
\hline $\begin{array}{l}\text { Meyerhardt } 2012 \text { b [13] } \\
\text { Subtotal }(95 \% \mathrm{Cl})\end{array}$ & 18.8 & 20.869 & $\begin{array}{r}139 \\
139\end{array}$ & 16.6 & 32.5892 & $\begin{array}{l}128 \\
128\end{array}$ & $\begin{array}{l}5.8 \% \\
5.8 \%\end{array}$ & $\begin{array}{l}2.20[-4.43,8.83] \\
2.20[-4.43,8.83]\end{array}$ & & & & \\
\hline \multicolumn{13}{|c|}{$\begin{array}{l}\text { Heterogeneity: Not applicable } \\
\text { Test for overall effect: } Z=0.65(P=0.52)\end{array}$} \\
\hline \multicolumn{13}{|c|}{ 1.1.3 c) BEVA + FOLFOX vs FOLFOX } \\
\hline Meyerhardt 2012 a [13] & 18.9 & 18.0623 & 744 & 19.45 & 24.1635 & 936 & $9.8 \%$ & $-0.55[-2.57,1.47]$ & & & & \\
\hline $\begin{array}{l}\text { Suenaga } 2014[83] \\
\text { Subtotal }(95 \% \mathrm{Cl})\end{array}$ & 38.85 & 27.4177 & $\begin{array}{r}84 \\
828\end{array}$ & 20.45 & 19.7229 & $\begin{array}{r}121 \\
1057\end{array}$ & $\begin{array}{r}5.6 \% \\
15.5 \%\end{array}$ & $\begin{array}{r}18.40[11.56,25.24] \\
8.63[-9.93,27.19]\end{array}$ & & & & \\
\hline \multicolumn{13}{|c|}{$\begin{array}{l}\text { Heterogeneity: } \mathrm{Tau}^{2}=172.94 ; \mathrm{Chi}^{2}=27.15, \mathrm{df}=1(\mathrm{P}<0.00001) ; \mathrm{I}^{2}=96 \% \\
\text { Test for overall effect: } Z=0.91(P=0.36)\end{array}$} \\
\hline \multicolumn{13}{|c|}{ 1.1.4 d) BEVA + CT vs CETUX + CT } \\
\hline Basso 2016 [86] & 28.8 & 153.9588 & 39 & 42.1 & 212.8148 & 35 & $0.1 \%$ & $-13.30[-98.77,72.17]$ & $\leftarrow$ & & & \\
\hline Deng 2015 [74] & 42 & 37.4393 & 8 & 39 & 36.5985 & 18 & $0.6 \%$ & $3.00[-27.97,33.97]$ & & & & \\
\hline Bai 2016 [87] & 27.7 & 34.7521 & 188 & 28.3 & 28.367 & 101 & $5.2 \%$ & $-0.60[-8.04,6.84]$ & & & & \\
\hline $\begin{array}{l}\text { Yang } 2014[77] \\
\text { Subtotal }(95 \% \mathrm{Cl})\end{array}$ & 30 & 383.7594 & $\begin{array}{r}95 \\
330\end{array}$ & 37 & 384.5957 & $\begin{array}{r}63 \\
217\end{array}$ & $\begin{array}{l}0.0 \% \\
5.9 \%\end{array}$ & $\begin{array}{r}-7.00[-129.37,115.37] \\
-0.52[-7.71,6.67]\end{array}$ & & & & \\
\hline \multicolumn{13}{|c|}{$\begin{array}{l}\text { Heterogeneity: } \mathrm{Tau}^{2}=0.00 ; \mathrm{Chi}^{2}=0.15, \mathrm{df}=3(\mathrm{P}=0.99) ; \mathrm{I}^{2}=0 \% \\
\text { Test for overall effect: } Z=0.14(P=0.89)\end{array}$} \\
\hline \multicolumn{13}{|c|}{ 1.1.5 e) BEVA + CT vs noBBP + CT } \\
\hline Cartwright 2012 [73] & 27.7 & 23.2373 & 267 & 22 & 20.4463 & 306 & $8.5 \%$ & $5.70[2.09,9.31]$ & & & & \\
\hline Grothey 2008 [85] & 31.8 & 50.3226 & 642 & 20 & 23.4604 & 531 & $7.8 \%$ & $11.80[7.43,16.17]$ & & & & \\
\hline Grothey 2014 [84] & 14.6 & 13.8429 & 438 & 10.7 & 15.7836 & 667 & $10.0 \%$ & $3.90[2.13,5.67]$ & & & - & \\
\hline Hurwitz 2014 [42] & 19.6 & 19.8474 & 210 & 17.65 & 25.5501 & 272 & $8.1 \%$ & $1.95[-2.10,6.00]$ & & & & \\
\hline $\begin{array}{l}\text { Moscetti } 2013[81] \\
\text { Subtotal }(95 \% \mathrm{CI})\end{array}$ & 22.5 & 19.1975 & $\begin{array}{r}118 \\
1675\end{array}$ & 21 & 15.2735 & $\begin{array}{r}102 \\
1878\end{array}$ & $\begin{array}{r}7.6 \% \\
42.0 \%\end{array}$ & $\begin{array}{l}1.50[-3.06,6.06] \\
4.89[1.91,7.87]\end{array}$ & & & & \\
\hline \multicolumn{13}{|c|}{$\begin{array}{l}\text { Heterogeneity: } \text { Tau }^{2}=8.03 ; \mathrm{Chi}^{2}=14.75, \mathrm{df}=4(P=0.005) ; I^{2}=73 \% \\
\text { Test for overall effect: } Z=3.22(P=0.001)\end{array}$} \\
\hline Total $(95 \% \mathrm{Cl})$ & & & 5278 & & & 5816 & $100.0 \%$ & $4.07[1.69,6.45]$ & & & & \\
\hline \multicolumn{7}{|c|}{$\begin{array}{l}\text { Heterogeneity: } \text { Tau}^{2}=13.94 ; \mathrm{Chi}^{2}=78.04, \mathrm{df}=15(P<0.00001) ; \mathrm{I}^{2}= \\
\text { Test for overall effect: } Z=3.35(P=0.0008) \\
\text { Test for subgroup differences: } \mathrm{Chi}^{2}=2.54, \mathrm{df}=4(P=0.64), \mathrm{I}^{2}=0 \%\end{array}$} & & & -20 & noBEVA & 10 & 20 \\
\hline
\end{tabular}

Fig. 1 Overall survival forest plot

no BBP grouping, we noticed that the reduction in the heterogeneity of this grouping was reduced from $I^{2}=73 \%$ to $I^{2}=0 \%$. The general heterogeneity was reduced from $I^{2}=68 \%$ to $I^{2}=59 \%$, and there was no change in the clinical outcome direction, with a statistically significant difference between the interventions $(p<0.00001)$

\subsubsection{Progression-Free Survival}

We included 11 studies on PFS with 3704 participants. There were significant differences between the groups BEVA versus no BEVA ( $\mathrm{MD}=2.85$; 95\% CI 0.74-4.96; $\left.p=0.008 ; I^{2}=94 \%\right)$. We performed the sensitivity analyses in the intervention subgroups because of the high statistical heterogeneity $\left(I^{2}=94 \% ; p<0.00001\right)$ (Table 3; Fig. 2).
In this analysis, the individual exclusion of studies of any intervention group neither reduced the high heterogeneity nor changed the outcome. However, the combined exclusion of studies, namely Hurwitz et al. [42] with BEVA versus no BEVA, Varol et al. [76] with BEVA + FOLFOX versus FOLFOX, Varol et al. [76] with BEVA + FOLFIRI versus FOLFIRI, and Turan et al. [82] on BEVA versus CT, showed $\mathrm{MD}=3.30,95 \%$ CI $2.17-4.42, p<0.00001$, and $I^{2}=0 \%$.

\subsubsection{Post-Progression Survival}

For PPS, we included three studies with 2851 participants. These three studies only assessed the effect of BEVA versus the no BBP intervention subgroup [73, 84, 85]. It was noted that the results of the meta-analysis demonstrated a significant benefit in PPS for patients treated with BEVA 


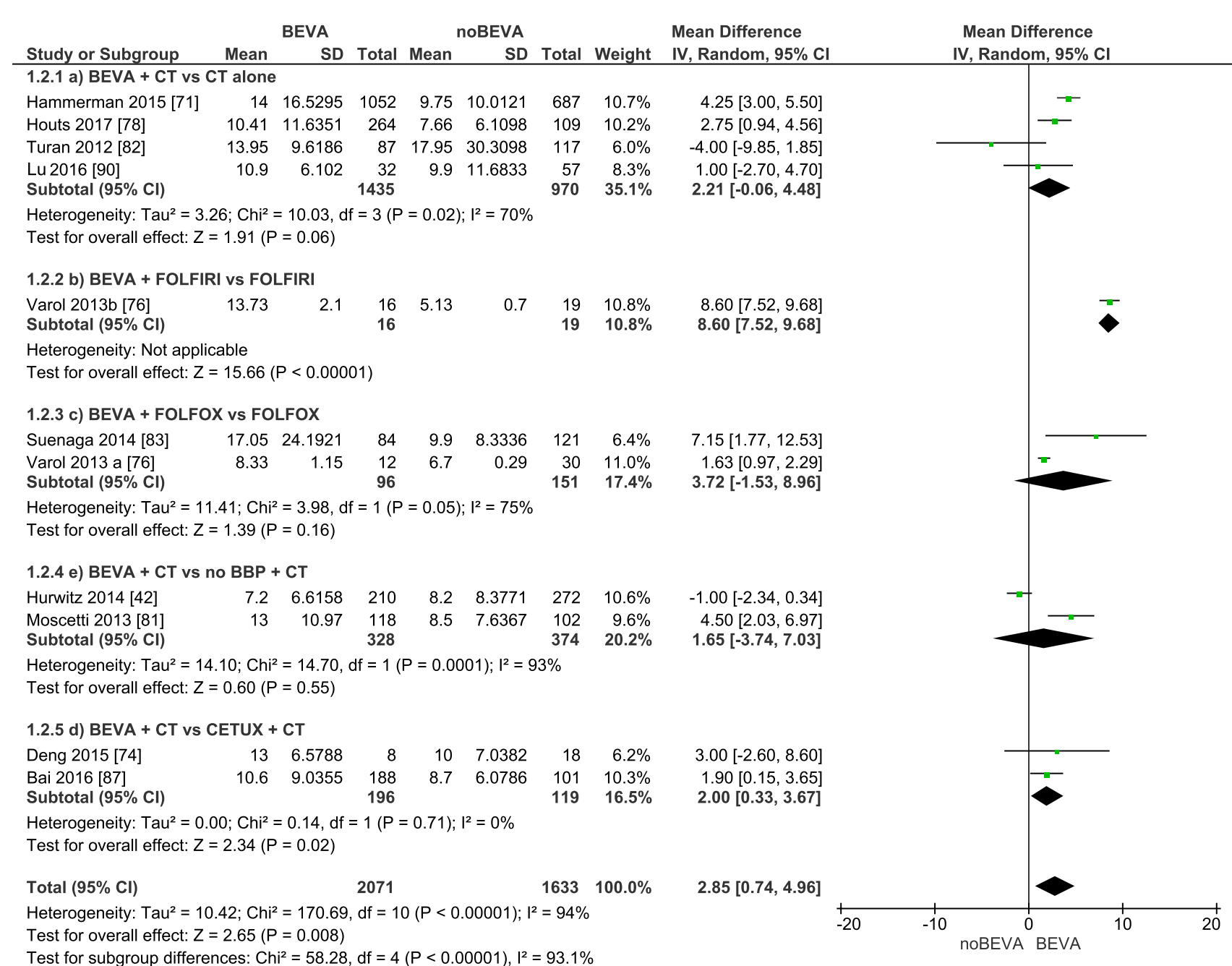

Fig. 2 Progression-free survival forest plot

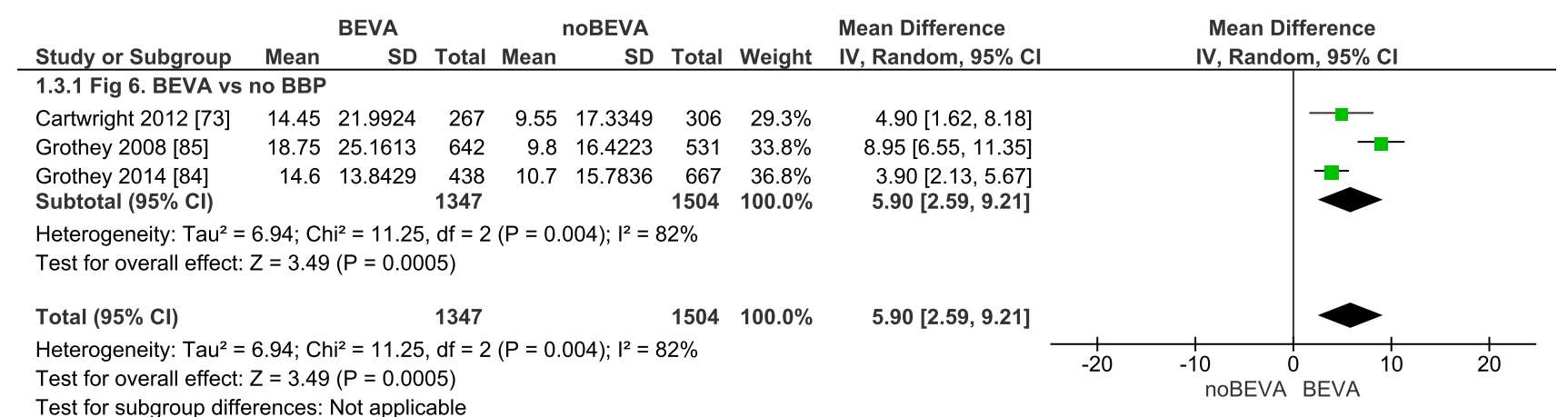

Fig. 3 Post-progression survival forest plot 
$(\mathrm{MD}=5.9 ; 95 \%$ CI $2.59-9.21 ; p=0.0005)$ and high statistical heterogeneity $\left(I^{2}=82 \% ; p=0.004\right)$. In the sensitivity analysis, the exclusion of the study conducted by Grothey et al. [84] indicated reduced heterogeneity $\left(I^{2}=0 \%\right.$; $\mathrm{MD}=4.12 ; 95 \% \mathrm{CI} 2.57-5.68 ; p<0.00001)$ without changing the direction of the outcome (Table 3; Fig. 3).

\subsection{Secondary Outcomes}

For secondary outcomes, we analyzed 571 participants from five studies on the response rate or disease control rate measured by the RECIST scale [74, 77, 80, 82] and 1897 participants from two studies regarding the metastasectomy rate $[71,77]$.

In the meta-analysis, we assessed eight studies that had described severe adverse events [72, 77, 83-85, 88, 89] for safety, including hypertension, arterial thromboembolism, venous thromboembolism, gastrointestinal perforation, bleeding, diarrhea, neutropenia, and other severe adverse events (Table 4).

The meta-analyses that assessed the disease control rate $[74,77,80,83,90]$ did not show any statistically significant differences between BEVA and no BEVA interventions. The comparison revealed low heterogeneity $\left(I^{2}=10 \% ; p=0.18\right)$

With respect to the metastasectomy rate [71, 77], there were statistically significant differences for BEVA $(p<0.0001)$ in comparison to no BEVA intervention. The meta-analysis showed no heterogeneity (Fig. 4).

Regarding adverse events, there were no statistically significant differences between the interventions for arterial and venous thromboembolism, bleeding, diarrhea, neutropenia, and other severe adverse events (Table 4)

Table 4 Severe adverse events (grade $\geq 3$ )

\begin{tabular}{lllll}
\hline Outcomes & Studies $n$ (references) & Participants & Estimated effect/[95\% CI]/(p value) & $I^{2}(p$ value $)$ \\
\hline Hypertension & $3[76,84,85]$ & 2436 & $1.36[1.09-1.71](p=0.007)$ & $2 \%(p=0.36)$ \\
Arterial thromboembolism & $4[72,81,84,85]$ & 2948 & $0.89[0.63-1.26](p=0.51)$ & $0 \%(p=0.81)$ \\
Venous thromboembolism & $4[13,77,81,84]$ & 4009 & $0.97[0.82-1.13](p=0.66)$ & $0 \%(p=0.79)$ \\
GI Perforation & $5[13,77,81,84,85]$ & 5182 & $1.89[0.99-3.59](p=0.05)$ & $17 \%(p=0.31)$ \\
Bleeding & $4[77,84,85,90]$ & 2525 & $1.71[0.80-3.65](p=0.17)$ & $26 \%(p=0.26)$ \\
Diarrhea & $2[77,83]$ & 371 & $0.63[0.17-2.31](p=0.49)$ & $0 \%(p=0.49)$ \\
Neutropenia & $2[77,83]$ & 371 & $1.19[0.90-1.58](p=0.22)$ & $0 \%(p=0.40)$ \\
Others events & $4[74,83,84,90]$ & 1565 & $1.27[0.66-2.45](p=0.48)$ & $8 \%(p=0.35)$ \\
\hline
\end{tabular}

CI confidence interval, GI gastrointestinal, $I^{2}$ heterogeneity

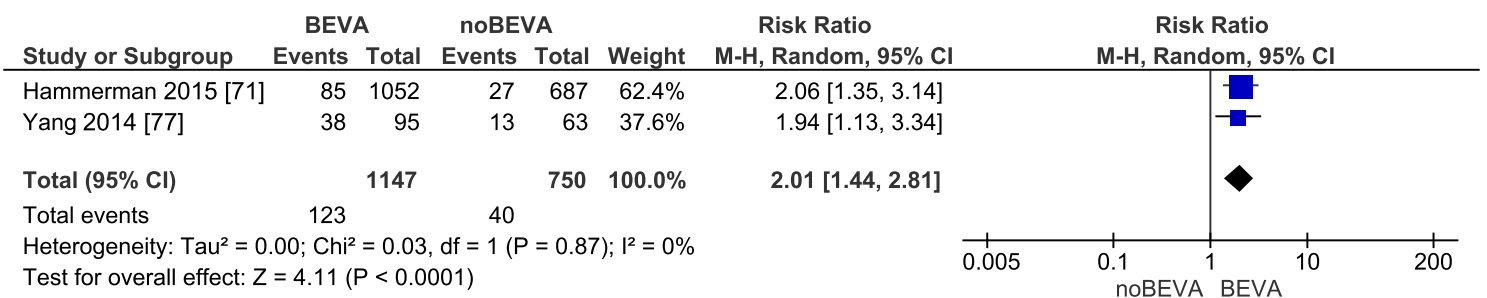

Fig. 4 Metastasectomy rate forest plot

\begin{tabular}{|c|c|c|c|c|c|c|c|c|c|c|}
\hline \multirow[b]{2}{*}{ Study or Subgroup } & \multicolumn{2}{|c|}{ BEVA } & \multicolumn{2}{|c|}{ noBEVA } & \multirow[b]{2}{*}{ Weight } & \multirow{2}{*}{$\begin{array}{c}\text { Risk Ratio } \\
\text { M-H, Random, } 95 \% \mathrm{Cl} \\
\end{array}$} & & \multirow{2}{*}{\multicolumn{2}{|c|}{$\begin{array}{c}\text { Risk Ratio } \\
\text { M-H, Random, } 95 \% \mathrm{Cl} \\
\end{array}$}} & \\
\hline & Events & Total & Events & Total & & & & & & \\
\hline Grothey 2008 [85] & 10 & 642 & 8 & 531 & $33.7 \%$ & $1.03[0.41,2.60]$ & & & & \\
\hline Grothey 2014 [84] & 5 & 438 & 0 & 667 & $4.7 \%$ & $16.74[0.93,301.94]$ & & & & \\
\hline Meyerhardt $2012[13,88]$ & 21 & 903 & 16 & 1623 & $52.1 \%$ & $2.36[1.24,4.50]$ & & & & \\
\hline Moscetti 2013 [81] & 1 & 118 & 1 & 102 & $5.2 \%$ & $0.86[0.05,13.65]$ & & & & \\
\hline Yang 2014 [77] & 2 & 95 & 0 & 63 & $4.4 \%$ & $3.33[0.16,68.29]$ & & & & \\
\hline Total $(95 \% \mathrm{Cl})$ & & 2196 & & 2986 & $100.0 \%$ & $1.89[0.99,3.59]$ & & & & \\
\hline Total events & 39 & & 25 & & & & & & & \\
\hline $\begin{array}{l}\text { Heterogeneity: } \mathrm{Tau}^{2}=0.10 \\
\text { Test for overall effect: } Z=\end{array}$ & $\begin{array}{l}10 ; \mathrm{Chi}^{2} \\
=1.94(\mathrm{~F}\end{array}$ & $\begin{array}{l}=4.80 \\
P=0.0\end{array}$ & df $=4(P$ & $=0.31$ & )$; l^{2}=17 \%$ & & 0.01 & 0.1 & BEVA & 100 \\
\hline
\end{tabular}

Fig. 5 GI perforation forest plot. GI gastrointestinal 
With respect to gastrointestinal perforation (Fig. 5), we assessed five studies with 5182 participants. There was a borderline statistical difference, with a relative risk of 1.89 , 95\% CI 0.99-3.59, $p=0.05$, and $I^{2}=17 \%$. We performed a sensitivity analysis excluding the study conducted by Grothey et al. [84]. We obtained a relative risk of 2.48 (95\% CI 1.36-4.53), $p=0.003$, and $I^{2}=0 \%$, favoring the risk of an event occurring with BEVA.

There were statistically significant differences for hypertension demonstrating the risk for this event with BEVA in comparison to no BEVA $(p=0.007)$. The meta-analysis indicated low heterogeneity (Fig. 6). Table 4 shows in detail the outcomes of severe adverse reactions comparing BEVA with no BEVA schemes.

\subsection{Conflict of Interest}

For the COI, we included nine studies with 8049 participants. These nine studies evaluated the overall quality effect of the studies of the BEVA versus no BEVA [13, $42,71,73,74,81,83-85]$. It was noted that the results of the meta-analysis demonstrated a significant difference in the COI subgroup for patients treated with BEVA $(\mathrm{MD}=4.85 ; 95 \%$ CI $2.30-7.40 ; p=0.0002)$ and high statistical heterogeneity $\left(I^{2}=74 \%, p=0.004\right)$ (see the electronic supplementary material, Fig. 5E). The overall effect of the combined subgroups (COI and no COI) was also highly significant for patients treated with BEVA $(p<0.00001)$. Consequently, some of the studies may have been influenced by publication bias, as shown by funnel plots.

\subsection{Quality of the Studies (Newcastle-Ottawa Scale)}

We included 19 studies with 9856 participants for BEVA versus no BEVA [13, 42, 71-74, 76-78, 80-87, 90]. There was a significant difference in the subgroup with a quality of seven or more stars for patients treated with BEVA $(\mathrm{MD}=4.52 ; 95 \%$ CI $3.26-7.10 ; p<0.00001)$ and a high statistical heterogeneity $\left(I^{2}=90 \% ; p=0.0001\right)$ (see the electronic supplementary material, Fig. 6E).

\section{Discussion}

Among the assessed MoAbs, BEVA had been assessed in the largest number of studies. The studies on effectiveness comparing BEVA and no BEVA groups demonstrated statistically significant and clinically relevant benefits in patients treated with BEVA principally around OS, PFS, PPS and metastasectomy rates, but not in the disease control rate.

With respect to OS, patients given BEVA in combination with fluoropyrimidine-based CT regimens showed similar results across studies; however, better results (outcomes) were found when this comparison was made with patients who received BEVA versus CETUX. Analysis of the subgroup of patients given maintenance of treatment with BEVA versus no BBP showed patients had better results with BEVA + CT compared to those when BEVA was suspended and patients were maintained on CT alone (FOLFIRI or FOLFOX) when their disease progressed.

However, the effect on OS, PFS and PPS indicated significant heterogeneity, which is probably attributable to differences in the effects of BEVA therapy in combination with different $\mathrm{CT}$ regimens. One explanation for these findings is that studies tend to be more homogeneous when the same combinations of fluoropyrimidine-based CT regimens are used with each comparator arm. In the sensitivity analysis, studies that clearly used BEVA + FOLFOX versus FOLFOX (oxaliplatin-based) alone showed high heterogeneity. When these studies were excluded from the analysis, we observed a reduction in heterogeneity to acceptable levels without altering the clinical effects for the group.

However, in the PPS subgroup, this difference in timing of progression was statistically significant, and when the study of Grothey et al. [85] was excluded, a reduction of heterogeneity to $I^{2}=0 \%$ was observed.

The methodological quality of the various studies was moderate, with most studies funded by the pharmaceutical industry. This is important since previous meta-analyses conducted by our group and others have shown that studies funded by pharmaceutical companies tend to be more positive towards their medicines than those conducted by independent groups [57-59].

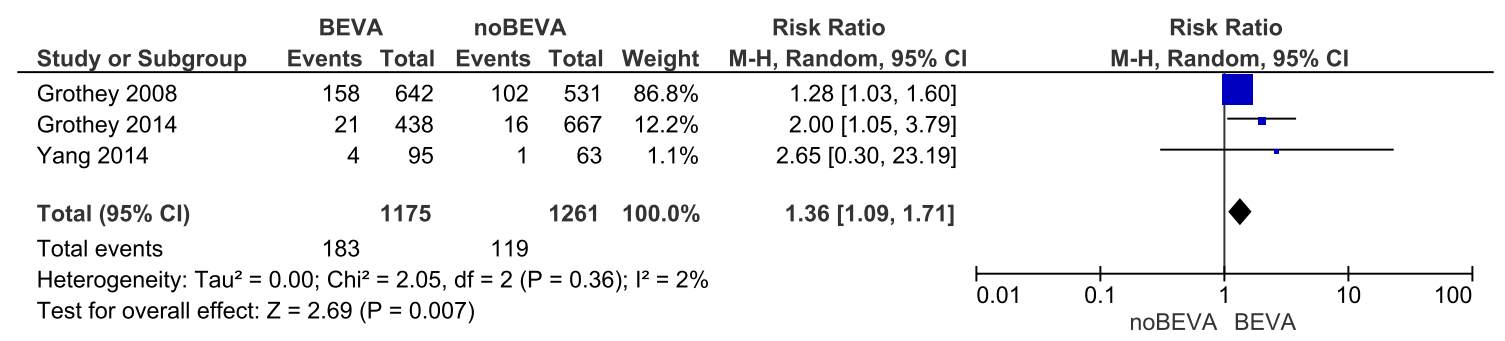

Fig. 6 Hypertension side effects forest plot 
In addition, high heterogeneity can also be attributed to the different treatment lines and different CT regimens associated with anti-angiogenic therapy, anti-epidermal growth factor differences related to the KRAS status (wild type of mutation status), differences in prognostic factors such as performance status, location of the primary tumor, and the location of the metastases. Declared differences in COI and the quality of the studies can also be considered potential sources of heterogeneity. However, in all these cases, a significant statistical heterogeneity of $I^{2}>75 \%$ can be expected.

The use of MoAbs as a therapeutic option for mCRC created expectations for greater OS, decreased toxicity and grade $\geq 3$ adverse event complications compared with previous cytotoxic CT used in mCRC patients. Notably, it was observed that BEVA had been a milestone in clinical oncology [91]. However, in reality, there was only a modest impact on OS versus current CT regimens.

The results of this meta-analysis point to a statistically significant advantage in favor of BEVA. This advantage may be considered clinically modest in relation to a longer life for patients with metastatic disease; however, this should be considered a considerable advance in terms of the choices and options available for combinations of fluoropyrimidinebased therapeutic regimens. The most important factor to note though is a statistically significant increase in severe adverse events associated with BEVA, especially severe hypertension and gastrointestinal perforation, which need to be factored into any decision.

Within Brazil, any modest improvement in effectiveness, coupled with a significant increase in severe adverse events with BEVA, needs to be balanced against the increasing number of successful litigations as well as the significant increase in costs and associated expenses with the MoAbs (Fig. 1E, electronic supplementary material). This reduces available resources for other priority disease areas; however, it increases the availability of these MoAb for diseases such as $\mathrm{mCRC}$ and cervical cancer, among others, which are not currently incorporated into the Brazilian health system. This raises the need for assessing their comparative effectiveness $[51,92]$ and as a therapeutic alternative capable of being incorporated into the Brazilian health system [93].

Our findings should also provide guidance to the judiciary when assessing potential funding decisions for these three MoAbs in patients with mCRC, similar to the situation with insulin glargine [54].

We did not find any previous systematic reviews assessing the effectiveness and safety of the different MoAbs relevant to the current situation. Some randomized studies had compared different treatment schemes combined or not with the MoAbs and showed conflicting results. Some studies indicated benefits, whereas others showed an increase in the toxicity profile of treatment without impacting on patients' survival [94-99].
The result of this analysis demonstrated that the patients prescribed BEVA spend more time without disease progression and had a higher rate of resection compared to the non-BEVA or other anti-EGFR containing regimens, and there were significant gains in OS when re-analyzed to reduce the heterogeneity of the included studies. With respect to safety, most studies in the meta-analyses indicated no significant reduction in severe adverse events using BEVA.

In a meta-analysis of Lv et al. [44], the efficacy and safety of adding BEVA to a therapy based on CETUX or PANIT for treating patients with $\mathrm{mCRC}$ were estimated. The authors suggested that the combination of anti-VEGF antibody (BEVA) and anti-EGFR antibody (CETUX and PANIT) had not improved PFS, OS, or the disease control rate when compared with the antibody alone. In addition, the incidence of grade $\geq 3$ adverse events was not significantly greater in BEVA groups when compared to CETUX/PANIT groups. There are a number of similarities with our study findings.

On the other hand, the meta-analysis conducted by Wagner et al. [47], which compared BEVA versus no BEVA as first-line CT, showed significant benefits in OS and PFS in patients treated with BEVA. We have previously pointed out that in the no BEVA group, in addition to the CT schemes, Wagner et al. [47] had used vatalanib (another VEGF inhibitor), which was not included in our review.

We believe this situation justified the need for additional re-evaluation as more data became available. There was a high incidence of grade 3 and 4 adverse events for arterial hypertension, arterial thromboembolic events and gastrointestinal perforations in our review, which may compromise patient safety. Observational studies included in this analysis, such as Meyerhardt et al. [88], Grothey et al. [84], and Yang et al. [77], agreed with the results found in the RCTs indicating the high patient risk of using BEVA. In the metaanalysis conducted by Hapani et al. [43], the incidence of gastrointestinal perforation was $0.9 \%$ for patients receiving BEVA, with mortality at $21.7 \%$.

Hurwitz et al. [100], comparing various CT schemes, combined or not with BEVA, as first- or second-line treatment, found that the addition of BEVA was associated with a significant gain in OS and PFS defined by the CT backbone (oxaliplatin-based, irinotecan-based) and the extent of disease (liver metastases only, extensive disease), which is in accordance with the present study. The inclusion of more recent studies suggests an increase in OS, especially when reducing the heterogeneity of included studies. In addition, the incidence of grade $\geq 3$ adverse events was higher in the group that received combinations with BEVA, confirming earlier studies.

With respect to safety, we emphasize that most outcomes of meta-analyses indicated no significant reduction in severe adverse events using BEVA. This implies that the promise 
to use the MoAbs to reduce adverse events has not yet been fulfilled [43, 47].

In the studies reviewed and compared in our systematic review, there were some differences compared with individual studies. Individual studies indicated improvements with an average survival duration close to 3 years, and high survival rates at 5 years, which means an increase of $20 \%$ compared to that seen in some trials with patients treated solely with CT [101]. However, for most patients, the improvement obtained with treatment would be palliative and not curative [102]. The main expectations are prolonging PPS and maintaining quality of life for as long as possible rather than improving OS.

It is important to recognize that $\mathrm{mCRC}$ is a chronic disease and that prolonging survival with $\mathrm{CT}$ regimens associated with biological agents is only typically seen for the PPS period, although there were modest improvements in OS with BEVA. However, it is necessary to evaluate the cost of new interventions according to the configuration of each health system and their associated costs for reimbursement and funding decisions. Marginal gains for high-cost medicines are not seen as acceptable if this restricts funding for other more effective interventions in this and other patient populations within health systems with universal access. This may well mean denying effective treatment options in other high-priority disease areas, which is increasingly difficult to justify within finite budgets $[28,61,103]$. However, it is important to note that advances made in first-line treatment will also be applied to the second-line treatment [4].

In addition, assessments of adverse events have typically only been carried out for severe cases. In our review, we did not assess the effect that adverse events have on patients' quality of life, i.e., BEVA-induced dysphonia (necrosis of the vocal cords) and hearing loss due to BEVA, given that they were not life threatening.

Another important finding was the COI seen in some of the studies, which Thompson and others [104, 105] consider to be a set of study conditions in which professional judgment could be unduly influenced by interests such as financial gain. Scientific publications that present a COI with pharmaceutical companies can be a concern as they can be persuasive and avoid disclosing negative results, more frequently have favorable results towards the sponsor's medicine, or even influence the delay in disclosing these results as a strategy to protect potential markets [106-110]. Some of the findings in the studies selected in this systematic review and meta-analysis may have been influenced by publication bias, as shown by funnel plots (see the electronic supplementary material, Figs. 3E.1 and 4E.2) as well as Fig. 5E, with the subgroups combined (COI and no COI) favoring patients treated with BEVA $(p<0.00001)$.

We also performed a meta-analysis to evaluate the quality of non-randomized studies, based on the quality assessment guideline made by the MOOSE tool, using the NewcastleOttawa scale. Low-quality studies may lead to a distortion of the summary of effect estimation (see the electronic supplementary material, Fig. 6E). Our findings show that there is a statistically significant difference between studies that were rated six stars or less and those rated seven stars or higher. Consequently, the high heterogeneity among the studies in this meta-analysis may be influenced proportionally by the quality of the studies.

We recognize this systematic review has some limitations. We only included observational studies, and the bias of this study design is its lack of randomization as well as uncontrolled confounding factors. Some studies did not provide complete and/or accurate information, excluding them from the quantitative analysis; consequently, hindering the understanding of the heterogeneity found in some comparison groups. In addition, only five studies assessed the effect of discontinuing BEVA beyond disease progression, and most of the studies did not use the same combinations or treatment schemes, although 16 of the 21 studies had used a CT scheme combined with fluorouracil.

Therapeutic care (in terms of the types of interventions, therapeutic schemes, and the level of expertise) was also rarely described in detail in these studies.

However, despite these limitations, we believe that our findings are robust in view of our methodological approach. This was confirmed by the sensitivity analysis where the inclusion and exclusion of studies in each comparison did not change the direction of most outcomes; however, significant changes were observed in heterogeneity.

\section{Conclusions}

The results of this meta-analysis point to a statistically significant advantage in favor of BEVA for the outcomes of OS, PFS, PPS, and the metastasectomy rate. This advantage may be considered clinically modest in relation to the patient's lifetime in the metastatic stage. This increases the choices for combining BEVA with fluoropyrimidine-based regimens, but we must not overlook the quality of life of these patients. This is because one of the most important factors to be observed with BEVA is the statistically significant increase in adverse events associated with its use, especially severe hypertension and gastrointestinal perforation.

This review also emphasized that studies directly comparing the effectiveness and safety of MoAbs in patients with mCRC are currently scarce, which needs to be addressed when payers are faced with funding choices. There is also a need for further observational studies to assess OS and adverse events comparing MoAbs associated with the different CT regimens given current concerns with their impact on OS in reality. 
These findings combined with those from RCTs can be used to update clinical guidelines to systematically promote better and more appropriate healthcare within universal healthcare systems through establishing the magnitude of benefits, risks, and costs, relating to specific aspects of patient care. In addition, it is hoped this review will also be of interest to the judiciary when authorizing resources for high-cost medicines with limited benefits, as this means less funds are available for valuable medicines in other priority areas.

\section{Compliance with Ethical Standards}

Funding The research was supported by the Research Group on Pharmacoepidemiology (GPFE), Centro Colaborador do SUS (CCATES) and Research Group on Health Economics (GPES) of UFMG. This systematic review is an integral part of the research project "Economic evaluation of monoclonal antibody treatments in metastatic colorectal cancer," with financial support from the National Council for Scientific and Technological Development $(\mathrm{CNPq})$, the Minas Gerais State Agency for Research and Development (FAPEMIG) and the Coordination for the Improvement of Higher Education Personnel (CAPES).

Conflict of interest Wânia Cristina da Silva, Vânia Eloisa de Araujo, Ellias Magalhães e Abreu Lima, Jessica Barreto Ribeiro dos Santos, Michael Ruberson Ribeiro da Silva, Paulo Henrique Ribeiro Fernandes Almeida, Francisco de Assis Acurcio, Brian Godman, Amanj Kurdi, Mariângela Leal Cherchiglia, and Eli Iola Gurgel Andrade declare that they have no conflicts of interest that might influence the results of the investigation.

Data availability All the papers incorporated into this systematic review and meta-analysis have been fully referenced.

Open Access This article is distributed under the terms of the Creative Commons Attribution-NonCommercial 4.0 International License (http://creativecommons.org/licenses/by-nc/4.0/), which permits any noncommercial use, distribution, and reproduction in any medium, provided you give appropriate credit to the original author(s) and the source, provide a link to the Creative Commons license, and indicate if changes were made.

\section{References}

1. Ellen 't Hoen L. Access to cancer treatment: a study of medicine pricing issues with recommendations for improving access to cancer medication [Internet]. World Health Organization. 2014 [cited 2018 Jan]. Available from: http://apps.who.int/medicinedo $\mathrm{cs} / \mathrm{en} / \mathrm{d} / \mathrm{Js} 21758 \mathrm{en} /$.

2. WHO I Cancer. 2018 Jan 30 [cited 2018 Jan 31]; Available from: http://www.who.int/cancer/en/.

3. IARC. GLOBOCAN-Estimated colorectal cancer mortality worldwide in 2012 [Internet]. GLOBOCAN. 2012. Available from: http://globocan.iarc.fr/Pages/fact_sheets_cance r.aspx? cancer $=$ colorectal.

4. Noonan AM, Bekaii-Saab T. Second-line outcomes in metastatic colorectal cancer-raising the bar for the high jump rather than the doing the limbo. Expert Rev Pharmacoecon Outcomes Res
[Internet]. 2014;15(1):133-43. Available from: http://dx.doi. org/10.1586/14737167.2015.972376.

5. Van Cutsem E, Cervantes A, Nordlinger B, Arnold D, ESMO Guidelines Working Group. Metastatic colorectal cancer: ESMO Clinical Practice Guidelines for diagnosis, treatment and followup. Ann Oncol [Internet]. 2014;25(Suppl 3):iii1-9. Available from: http://dx.doi.org/10.1093/annonc/mdu260.

6. Cordeiro F. Diretrizes para diagnóstico, estadiamento e tratamento cirúrgico e multidisciplinar do câncer colorretal. Revista da Associação Médica Brasileira [Internet]. 2004;50(1):10-1. Available from: http://dx.doi.org/10.1590/s0104-4230200400 0100017.

7. University of Luxembourg. "New biomarkers for colorectal cancer." ScienceDaily. www.sciencedaily.com/relea ses/2018/01/180111101419.htm. Accessed 6 Apr 2018.

8. Wardle J, Robb K, Vernon S, Waller J. Screening for prevention and early diagnosis of cancer. Am Psychol. 2015;70:119-33.

9. Mitry E, Fields ALA, Bleiberg H, Labianca R, Portier G, Tu D, et al. Adjuvant chemotherapy after potentially curative resection of metastases from colorectal cancer: a pooled analysis of two randomized trials. J Clin Oncol [Internet]. 2008;26(30):4906-11. Available from: http://dx.doi.org/10.1200/JCO.2008.17.3781.

10. Rougier P, Mitry E. Cancers colorectaux avant et après les biothérapies : une révolution dans la prise en charge des patients ? Gastroentérologie Clinique et Biologique [Internet]. 2009;33(89):672-80. Available from: http://dx.doi.org/10.1016/j. gcb.2009.07.019.

11. de Gramont A, Figer A, Seymour M, Homerin M, Hmissi A, Cassidy J, et al. Leucovorin and fluorouracil with or without oxaliplatin as first-line treatment in advanced colorectal cancer. J Clin Oncol [Internet]. 2000;18(16):2938-47. Available from: http://dx.doi.org/10.1200/jco.2000.18.16.2938.

12. Yamaguchi T, Iwasa S, Nagashima K, Ikezawa N, Hamaguchi $\mathrm{T}$, Shoji $\mathrm{H}$, et al. Comparison of panitumumab plus irinotecan and cetuximab plus irinotecan for KRAS wild-type metastatic colorectal cancer. Anticancer Res [Internet]. 2016;36(7):3531-6. Available from: https://www.ncbi.nlm.nih.gov/pubmed/27354 619.

13. Meyerhardt JA, Li L, Sanoff HK, Carpenter W, Schrag D. Effectiveness of bevacizumab with first-line combination chemotherapy for medicare patients with stage IV colorectal cancer. J Clin Oncol [Internet]. 2012;30(6):608-15. Available from: http:// dx.doi.org/10.1200/jco.2011.38.9650.

14. Tournigand C, Bengrine-Lefevre L. Quelles nouvelles stratégies dans le traitement du cancer colorectal métastatique avec les biothérapies ? Rev Med Interne [Internet]. 2009;30(5):411-5. Available from: http://dx.doi.org/10.1016/j.revmed.2008.12.015.

15. National Comprehensive Cancer Network ${ }^{\circledR}\left(\mathrm{NCCN}^{\circledR}\right)$. NCCN Guidelines for Patients ${ }^{\circledR}$ : colon cancer, version 1. 2016. Available from: https://books.google.com/books/about/NCCN_Guide lines_for_Patients.html?hl=\&id=BLPuvQAACAAJ.

16. Kelly RJ, Smith TJ. Delivering maximum clinical benefit at an affordable price: engaging stakeholders in cancer care. Lancet Oncol. 2014;15(3):e112-8.

17. Prasad V, Wang R, Afifi SH, Mailankody S. The rising price of cancer drugs—a new old problem? JAMA Oncol. 2017;3(2):277.

18. Editorial. The price of drugs for chronic myeloid leukemia (CML) is a reflection of the unsustainable prices of cancer drugs: from the perspective of a large group of CML experts. Blood. 2013;121(22):4439-42.

19. Fojo T, Lo AW. Price, value, and the cost of cancer drugs. Lancet Oncol. 2016:17:3-5.

20. Goldstein DA, Clark J, Tu Y, Zhang J, Fang F, Goldstein R, et al. A global comparison of the cost of patented cancer drugs in relation to global differences in wealth. Oncotarget. 2017;8(42). Available from: http://dx.doi.org/10.18632/oncotarget.17742. 
21. Howard DH, Bach PB, Berndt ER, Conti RM. Pricing in the market for anticancer drugs. J Econ Perspect. 2015;29(1):139-62.

22. Ghinea H, Kerridge I, Lipworth W. If we don't talk about value, cancer drugs will become terminal for health systems. The Conversation. 2015. Available from:https://ses.library.usyd.edu.au/ bitstream/2123/13653/2/TheConv_if-we-dont-talk-about-value -2015.pdf.

23. Chalkidou K, Marquez P, Dhillon PK, Teerawattananon Y, Anothaisintawee T, Gadelha CA, et al. Evidence-informed frameworks for cost-effective cancer care and prevention in low, middle, and high-income countries. Lancet Oncol. 2014;15(3):e119-31.

24. Konda B, Shum H, Rajdev L. Anti-angiogenic agents in metastatic colorectal cancer. World J Gastrointest Oncol [Internet]. 2015;7(7):71-86. Available from: http://dx.doi.org/10.4251/ wjgo.v7.i7.71.

25. Noonan AM, Bekaii-Saab T. Second-line outcomes in metastatic colorectal cancer-raising the bar for the high jump rather than the doing the limbo. Expert Rev Pharmacoecon Outcomes Res [Internet]. 2014;15(1):133-43. Available from: http://dx.doi.org/10.1586/14737167.2015.972376.

26. Fojo T, Grady C. How much is life worth: cetuximab, nonsmall cell lung cancer, and the $\$ 440$ billion question. J Natl Cancer Inst. 2009;101:1044-8.

27. Godman B, Wild C, Haycox A. Patent expiry and costs for anticancer medicines for clinical use. Generics Biosimilars Initiat J [Internet]. 2017;6(3):105-6. Available from: http://dx.doi. org/10.5639/gabij.2017.0603.021.

28. Haycox A. Why cancer? PharmacoEconomics. 2016;34(7):625-7.

29. Khambata-Ford S, Garrett CR, Meropol NJ, Basik M, Harbison $\mathrm{CT}, \mathrm{Wu} \mathrm{S}$, et al. Expression of epiregulin and amphiregulin and K-ras mutation status predict disease control in metastatic colorectal cancer patients treated with cetuximab. J Clin Oncol [Internet]. 2007;25(22):3230-7. Available from: http://dx.doi. org/10.1200/JCO.2006.10.5437.

30. Raskov H, Pommergaard H-C, Burcharth J, Rosenberg J. Colorectal carcinogenesis - update and perspectives. World J Gastroenterol [Internet]. 2014;20(48):18151-64. Available from: http://dx.doi.org/10.3748/wjg.v20.i48.18151.

31. Hsu H-C, Thiam TK, Lu Y-J, Yeh CY, Tsai W-S, You JF, et al. Mutations of KRAS/NRAS/BRAF predict cetuximab resistance in metastatic colorectal cancer patients. Oncotarget [Internet]. 2016;7(16):22257-70. Available from: http://dx.doi. org/10.18632/oncotarget.8076.

32. Shiroiwa T, Motoo Y, Tsutani K. Cost-effectiveness analysis of KRAS testing and cetuximab as last-line therapy for colorectal cancer. Mol Diagn Ther [Internet]. 2010;14(6):375-84. Available from: http://dx.doi.org/10.2165/11587610-00000 0000-00000.

33. Vijayaraghavan A, Efrusy MB, Göke B, Kirchner T, Santas CC, Goldberg RM. Cost-effectiveness of KRAS testing in metastatic colorectal cancer patients in the United States and Germany. Int J Cancer [Internet]. 2012;131(2):438-45. Available from: http:// dx.doi.org/10.1002/ijc.26400.

34. Godman B, Finlayson AE, Cheema PK, Zebedin-Brandl E, Gutiérrez-Ibarluzea I, Jones J, et al. Personalizing health care: feasibility and future implications. BMC Med [Internet]. 2013;11:179. Available from: http://dx.doi.org/10.1186/1741-7015-11-179.

35. SMC-SCOTTISH MEDICINES. [cited 2018 Mar 6]. Available from: https://www.scottishmedicines.org.uk/SMC_Advic e/Advice/Bevacizumab__Avastin__174___for_firstline_treat ment_of_patients_with_metastatic_cancer_of_the_colon_or_ rectum/Bevacizumab_100mg_4ml_and_400mg_16ml_solut ion_for_intravenous_infusion__Avastin.
36. Scotland N. Bevacizumab (Avastin ${ }^{\circledR}$ ) for first-line treatment of patients with metastatic cancer of the colon or rectum [Internet]. Scottish Medicines Consortium (SMC). 2006 [cited FEV 2018]. Available from: https://www.scottishmedicines.org.uk/ SMC_Advice/Advice/Bevacizumab_Avastin_174_for_first -line_treatment_of_patients_with_metastatic_cancer_of_the_ colon_or_rectum.

37. NICE-Bevacizumab and cetuximab for the treatment of metastatic colorectal cancer I Guidance and guidelines I NICE. [cited 2018 Mar 6]; Available from: https://www.nice.org.uk/guidance/ ta118.

38. Australian Government Department of Health. [cited 2018 Mar 6]. Available from: http://search.health.gov.au/s/searc h.html?query=Bevacizumab\&collection=health\&profile.

39. Australian Government Department of Health. Bevacizumab, solution for IV use. PBS-The Pharmaceutical Benefits Scheme [Internet]. Australia's Pharmaceutical Benefits Scheme (PBS). 2013 [cited Fev 2018]. Available from: http://www.pbs.gov.au/ info/industry/listing/elements/pbac-meetings/psd/2013-11/bevac izumab.

40. Bevacizumab for advanced colorectal cancer I CADTH.ca [Internet]. [cited 2018 Mar 6]. Available from: https://www.cadth.ca/ bevacizumab-advanced-colorectal-cancer- 0 .

41. Cetuximab, bevacizumab and panitumumab for the treatment of metastatic colorectal cancer after first-line chemotherapy: cetuximab (monotherapy or combination chemotherapy), bevacizumab (in combination with non-oxaliplatin chemotherapy) and panitumumab (monotherapy) for the treatment of metastatic colorectal cancer after first-line chemotherapy I Guidance and guidelines I NICE. [cited 2018 Mar 6]; Available from: https://www.nice. org.uk/guidance/ta242.

42. Hurwitz HI, Bekaii-Saab TS, Bendell JC, Cohn AL, Kozloff M, Roach N, et al. Safety and effectiveness of bevacizumab treatment for metastatic colorectal cancer: final results from the Avastin(®) Registry-Investigation of Effectiveness and Safety (ARIES) observational cohort study. Clin Oncol [Internet]. 2014;26(6):323-32. Available from: http://dx.doi.org/10.1016/j. clon.2014.03.001.

43. Hapani S, Chu D, Wu S. Risk of gastrointestinal perforation in patients with cancer treated with bevacizumab: a meta-analysis. Lancet Oncol [Internet]. 2009;10(6):559-68. Available from: http://dx.doi.org/10.1016/S1470-2045(09)70112-3.

44. Lv Y, Yang Z, Zhao L, Zhao S, Han J, Zheng L. The efficacy and safety of adding bevacizumab to cetuximab- or panitumumabbased therapy in the treatment of patients with metastatic colorectal cancer (mCRC): a meta-analysis from randomized control trials. Int J Clin Exp Med [Internet]. 2015;8(1):334-45. Available from: https://www.ncbi.nlm.nih.gov/pubmed/25785004.

45. Rosa B, de Jesus JP, de Mello EL, Cesar D, Correia MM. Effectiveness and safety of monoclonal antibodies for metastatic colorectal cancer treatment: systematic review and meta-analysis. Ecancermedicalscience [Internet]. 2015;9:582. Available from: http://dx.doi.org/10.3332/ecancer.2015.582.

46. Hurwitz HI, Yi J, Ince W, Novotny WF, Rosen O. The clinical benefit of bevacizumab in metastatic colorectal cancer is independent of K-ras mutation status: analysis of a phase III study of bevacizumab with chemotherapy in previously untreated metastatic colorectal cancer. Oncologist [Internet]. 2009;14(1):228. Available from: http://dx.doi.org/10.1634/theoncolog ist.2008-0213.

47. Wagner ADA, Arnold D, Grothey AAG, Haerting J, Unverzagt S. Anti-angiogenic therapies for metastatic colorectal cancer. Cochrane Database Syst Rev [Internet]. 2009; Available from: http://dx.doi.org/10.1002/14651858.cd005392.pub3.

48. CONITEC. Cetuximabe para o tratamento do câncer colorretal- Comissão Nacional de Incorporação de Tecnologias no 
SUS-CONITEC [Internet]. CONITEC-Comissão Nacional de Incorporação de Tecnologias no SUS. 2017 [cited 2018 Jan]. Available from: http://conitec.gov.br/images/Relatorios/2017/ Relatorio_Cetuximabe_cancer_colorretal_metastatico_.

49. CMED- Listas de preços de medicamentos - ANVISA [Internet]. [cited 2018 Mar 6]. Available from: http://portal.anvisa.gov.br/ listas-de-precos.

50. Giordano SH. Comparative effectiveness research in cancer with observational data. Am Soc Clin Oncol Educ Book [Internet]. 2015;e330-5. Available from: http://dx.doi.org/10.14694/EdBoo k_AM.2015.35.e330.

51. Dreyer NA, Tunis SR, Berger M, Ollendorf D, Mattox P, Gliklich R. Why observational studies should be among the tools used in comparative effectiveness research. Health Aff [Internet]. 2010;29(10):1818-25. Available from: http://dx.doi. org/10.1377/hlthaff.2010.0666.

52. Ma CKK, Danta M, Day R, Ma DDF. Dealing with the spiralling price of medicines: issues and solutions. Intern Med J [Internet]. 2018;48(1):16-24. Available from: http://dx.doi. org/10.1111/imj.13652.

53. Barron A, Wilsdon T. Challenging perceptions about oncology product pricing in breast and colorectal cancer. Pharmaceut Med [Internet]. 2016;30(6):321-6. Available from: http:// dx.doi.org/10.1007/s40290-016-0167-1.

54. Caires de Souza AL, de Souza ALC, de Assis Acurcio F, Júnior AAG, do Nascimento RCRM, Godman B, et al. Insulin glargine in a Brazilian state: should the government disinvest? An assessment based on a systematic review. Appl Health Econ Health Policy [Internet]. 2014;12(1):19-32. Available from: http://dx.doi.org/10.1007/s40258-013-0073-6.

55. Stroup DF, Berlin JA, Morton SC, Olkin I, Williamson GD, Rennie D, et al. Meta-analysis of observational studies in epidemiology: a proposal for reporting. Meta-analysis Of Observational Studies in Epidemiology (MOOSE) group. JAMA [Internet]. 2000;283(15):2008-12. Available from: https:// www.ncbi.nlm.nih.gov/pubmed/10789670.

56. Hartling L, Hamm M, Milne A, Vandermeer B, Santaguida PL, Ansari M, et al. Validity and inter-rater reliability testing of quality assessment instruments [Internet]. Rockville (MD): Agency for Healthcare Research and Quality (US); 2012. Available from: https://www.ncbi.nlm.nih.gov/pubmed/22536 612.

57. Marra LP, Araújo VE, Silva TBC, Diniz LM, Guerra Junior AA, Acurcio FA, et al. Clinical effectiveness and safety of analog glargine in type 1 diabetes: a systematic review and meta-analysis. Diabetes Ther [Internet]. 2016;7(2):241-58. Available from: http://dx.doi.org/10.1007/s13300-016-0166-y.

58. Almeida PHRF, Silva TBC, de Assis Acurcio F, Guerra Júnior AA, Araújo VE, Diniz LM, et al. Quality of life of patients with type 1 diabetes mellitus using insulin analog glargine compared with NPH insulin: a systematic review and policy implications. Patient [Internet]. 2018 ; Available from: http://dx.doi. org/10.1007/s40271-017-0291-3.

59. Heres S, Davis J, Maino K, Jetzinger E, Kissling W, Leucht S. Why olanzapine beats risperidone, risperidone beats quetiapine, and quetiapine beats olanzapine: an exploratory analysis of headto-head comparison studies of second-generation antipsychotics. Am J Psychiatry. 2006;163:185-94.

60. Higgins JPT, Green S. Cochrane Handbook for Systematic Reviews of Interventions [Internet]. John Wiley \& Sons; 2011. p. 672. Available from: https://market.android.com/detai 1s?id=book-NKMg9sMM6GUC.

61. Kantarjian HM, Fojo T, Mathisen M, Zwelling LA. Cancer drugs in the United States: Justum Pretium-the just price. J Clin Oncol. 2013;31(28):3600-4.
62. Wild C, Grössmann N, Bonanno PV, Bucsics A, Furst J, Garuoliene $\mathrm{K}$, et al. Utilisation of the ESMO-MCBS in practice of HTA. Ann Oncol [Internet]. 2016;27(11):2134-6. Available from: http://dx.doi.org/10.1093/annonc/mdw297.

63. Cortazar P, Zhang L, Untch M, Mehta K, Costantino JP, Wolmark $\mathrm{N}$, et al. Pathological complete response and long-term clinical benefit in breast cancer: the $\mathrm{CTNeoBC}$ pooled analysis. Lancet [Internet]. 2014 Jul 12;384(9938):164-72. Available from: http:// dx.doi.org/10.1016/S0140-6736(13)62422-8.

64. Ellis LM, Bernstein DS, Voest EE, Berlin JD, Sargent D, Cortazar P, et al. American Society of Clinical Oncology perspective: raising the bar for clinical trials by defining clinically meaningful outcomes. J Clin Oncol [Internet]. 2014;32(12):1277-80. Available from: http://dx.doi.org/10.1200/jco.2013.53.8009.

65. Ferguson JS, Summerhayes M, Masters S, Schey S, Smith IE. New treatments for advanced cancer: an approach to prioritization. Br J Cancer. 2000;83(10):1268-73.

66. Gyawali B, Hey S, Kesselheim AS. A comparison of response patterns for progression-free survival and overall survival following treatment for cancer with pd-1 inhibitors: a meta-analysis of correlation and differences in effect sizes. JAMA Netw Open. 2018;1(2):e180416.

67. Paris V. Belloni A. Value in pharmaceutical pricing. Available at: http://www.oecd-ilibrary.org/social-issues-migration-healt h/value-in-pharmaceutical-pricing_5k43jc9v6knx-en. OECD Health Working Papers. https://doi.org/10.1787/5k43jc9v6k nx-en.

68. Henshall CSL, Eichler H-G, Lemgruber A, Longson C, O'Rourke $\mathrm{B}$, Tunis S. Understanding the role and evidence expectations of health technology assessment and coverage/payer bodies: what are they looking for, and how and why does this differ from what regulators require? Ther Innov Regul Sci. 2013;48(3):341-6.

69. Therasse P, Arbuck SG, Eisenhauer EA, Wanders J, Kaplan RS, Rubinstein L, et al. New guidelines to evaluate the response to treatment in solid tumors. European Organization for Research and Treatment of Cancer, National Cancer Institute of the United States, National Cancer Institute of Canada. J Natl Cancer Inst [Internet]. 2000;92(3):205-16. Available from: https://www.ncbi. nlm.nih.gov/pubmed/10655437.

70. NIH. Common Terminology Criteria for Adverse Events (CTCAE), NIH publication [Internet]. NIH-National Cancer Institute. 2010 [cited 2018 Jan]. Available from: https:// wiki.nci.nih.gov/display/VKC/Common+Terminology+Crite ria+for+Adverse+Events+FAQ.

71. Hammerman A, Greenberg-Dotan S, Battat E, Feldhamer I, Bitterman H, Brenner B. The "real-life" impact of adding bevacizumab to first-line therapy in metastatic colorectal cancer patients: a large Israeli retrospective cohort study. Acta Oncol [Internet]. 2014;54(2):164-70. Available from: http://dx.doi. org/10.3109/0284186x.2014.958532.

72. Al-Shamsi HO, Anjum M, Al Farsi A, Shen H, Linkins L-A, Cook RJ, et al. Thrombotic events in patients with metastatic colorectal cancer treated with FOLFIRI plus bevacizumab. J Clin Oncol [Internet]. 2013;31(4_suppl):540-540. Available from: http://dx.doi.org/10.1200/jco.2013.31.4_suppl.540.

73. Cartwright TH, Yim YM, Yu E, Chung H, Halm M, Forsyth M. Survival outcomes of bevacizumab beyond progression in metastatic colorectal cancer patients treated in US community oncology. Clin Colorectal Cancer [Internet]. 2012;11(4):238-46. Available from: http://dx.doi.org/10.1016/j.clcc.2012.05.005.

74. Deng Y, Cai Y, Lin J, Jiang L, Hu H. Survival of patients with KRAS wild-type metastatic colorectal cancer is identical after sequential treatment with cetuximab and bevacizumab regardless of the sequence-a retrospective single-center study. Gastroenterol Rep [Internet]. 2015;3(4):339-43. Available from: http:// dx.doi.org/10.1093/gastro/gov051. 
75. Dotan E, Devarajan K, James D'Silva A, Beck A, Kloth DD, Cohen SJ, et al. Patterns of use and tolerance of anti-epidermal growth factor receptor antibodies in older adults with metastatic colorectal cancer. Clin Colorectal Cancer [Internet]. 2014;13(3):192-8. Available from: http://dx.doi.org/10.1016/j. clcc.2014.05.003.

76. Varol U, Karaca B, Cakar B, Sezgin C, Karabulut B, Uslu R. Comparing time to disease progression of irinotecan and oxaliplatin-based chemotherapies in colorectal cancer patients with liver only metastasis. Am J Clin Oncol [Internet]. 2013;36(4):388-91. Available from: http://dx.doi.org/10.1097/coc.0b013e318248da7 c.

77. Yang Y-H, Lin J-K, Chen W-S, Lin T-C, Yang S-H, Jiang $\mathrm{J}-\mathrm{K}$, et al. Comparison of cetuximab to bevacizumab as the first-line bio-chemotherapy for patients with metastatic colorectal cancer: superior progression-free survival is restricted to patients with measurable tumors and objective tumor response-a retrospective study. J Cancer Res Clin Oncol [Internet]. 2014;140(11):1927-36. Available from: http://dx.doi. org/10.1007/s00432-014-1741-0.

78. Houts AC, Ogale S, Zafar Y, Hubbard JM, Satram-Hoang S, Sommer N, et al. Progression-free survival in patients receiving chemotherapy alone (C) or chemotherapy with bevacizumab (CB) for first-line treatment of KRAS mutant metastatic colorectal cancer in community oncology settings. J Gastrointest Cancer [Internet]. 2017; Available from: http://dx.doi. org/10.1007/s12029-017-0017-8.

79. Chung W-S, Park M-S, Shin SJ, Baek S-E, Kim Y-E, Choi JY, et al. Response evaluation in patients with colorectal liver metastases: RECIST version 1.1 versus modified CT criteria. AJR Am J Roentgenol [Internet]. 2012;199(4):809-15. Available from: http://dx.doi.org/10.2214/AJR.11.7910.

80. Pietrantonio F, Mazzaferro V, Miceli R, Cotsoglou C, Melotti F, Fanetti G, et al. Pathological response after neoadjuvant bevacizumab- or cetuximab-based chemotherapy in resected colorectal cancer liver metastases. Med Oncol [Internet]. 2015;32(7):182. Available from: http://dx.doi.org/10.1007/ s12032-015-0638-3.

81. Moscetti L, Nelli F, Fabbri MA, Sperduti I, Alesini D, Cortesi E, et al. Maintenance single-agent bevacizumab or observation after first-line chemotherapy in patients with metastatic colorectal cancer: a multicenter retrospective study. Invest New Drugs [Internet]. 2013;31(4):1035-43. Available from: http://dx.doi. org/10.1007/s10637-013-9936-9.

82. Turan N, Benekli M, Dane F, Unal OU, Kara HV, Koca D, et al. Adjuvant systemic chemotherapy with or without bevacizumab in patients with resected pulmonary metastases from colorectal cancer. Thoracic Cancer [Internet]. 2014;5(5):398-404. Available from: http://dx.doi.org/10.1111/1759-7714.12107.

83. Suenaga M, Mizunuma N, Matsusaka S, Shinozaki E, Ueno M, Yamaguchi T. Retrospective analysis on the efficacy of bevacizumab with FOLFOX as a first-line treatment in Japanese patients with metastatic colorectal cancer. Asia Pac J Clin Oncol [Internet]. 2014;10(4):322-9. Available from: http://dx.doi. org/10.1111/ajco.12094.

84. Grothey A, Flick ED, Cohn AL, Bekaii-Saab TS, Bendell JC, Kozloff M, et al. Bevacizumab exposure beyond first disease progression in patients with metastatic colorectal cancer: analyses of the ARIES observational cohort study. Pharmacoepidemiol Drug Saf [Internet]. 2014;23(7):726-34. Available from: http:// dx.doi.org/10.1002/pds.3633.

85. Grothey A, Sugrue MM, Purdie DM, Dong W, Sargent D, Hedrick E, et al. Bevacizumab beyond first progression is associated with prolonged overall survival in metastatic colorectal cancer: results from a large observational cohort study (BRiTE).
J Clin Oncol [Internet]. 2008;26(33):5326-34. Available from: http://dx.doi.org/10.1200/jco.2008.16.3212.

86. Basso M, Dadduzio V, Ardito F, Lombardi P, Strippoli A, Vellone $\mathrm{M}$, et al. Conversion chemotherapy for technically unresectable colorectal liver metastases: a retrospective, STROBEcompliant, single-center study comparing chemotherapy alone and combination chemotherapy with cetuximab or bevacizumab. Medicine [Internet]. 2016;95(20):e3722. Available from: http:// dx.doi.org/10.1097/MD.0000000000003722.

87. Bai L, Wang F, Li Z-Z, Ren C, Zhang D-S, Zhao Q, et al. Chemotherapy plus bevacizumab versus chemotherapy plus cetuximab as first-line treatment for patients with metastatic colorectal cancer: results of a registry-based cohort analysis. Medicine [Internet]. 2016;95(51):e4531. Available from: http://dx.doi. org/10.1097/MD.0000000000004531.

88. Meyerhardt JA, Li L, Sanoff HK, Carpenter W, Schrag D. Effectiveness of bevacizumab with first-line combination chemotherapy for medicare patients with stage IV colorectal cancer. J Clin Oncol [Internet]. 2012;30(6):608-15. Available from: http:// dx.doi.org/10.1200/jco.2011.38.9650.

89. Moscetti L, Nelli F, Fabbri MA, Sperduti I, Alesini D, Cortesi E, et al. Maintenance single-agent bevacizumab or observation after first-line chemotherapy in patients with metastatic colorectal cancer: a multicenter retrospective study. Invest New Drugs [Internet]. 2013;31(4):1035-43. Available from: http://dx.doi. org/10.1007/s10637-013-9936-9.

90. Lu Z-H, Peng J-H, Wang F-L, Yuan Y-F, Jiang W, Li Y-H, et al. Bevacizumab with preoperative chemotherapy versus preoperative chemotherapy alone for colorectal cancer liver metastases: a retrospective cohort study. Medicine [Internet]. 2016;95(35):e4767. Available from: http://dx.doi.org/10.1097/ MD.0000000000004767.

91. Hurwitz H, Fehrenbacher L, Novotny W, Cartwright T, Hainsworth J, Heim W, et al. Bevacizumab plus irinotecan, fluorouracil, and leucovorin for metastatic colorectal cancer. N Engl J Med [Internet]. 2004;350(23):2335-42. Available from: http://dx.doi. org/10.1056/NEJMoa032691.

92. Chang SM. The Agency for Healthcare Research and Quality (AHRQ) effective health care (EHC) program methods guide for comparative effectiveness reviews: keeping up-todate in a rapidly evolving field. $\mathrm{J}$ Clin Epidemiol [Internet]. 2011;64(11):1166-7. Available from: http://dx.doi.org/10.1016/j. jclinepi.2011.08.004.

93. Silva HP, Petramale CA, Elias FTS. Avanços e desafios da política nacional de gestão de tecnologias em saúde. Revista de Saúde Pública [Internet]. 2012;46(suppl 1):83-90. Available from: http://dx.doi.org/10.1590/s0034-89102012005000060.

94. Stathopoulos GP, Batziou C, Trafalis D, Koutantos J, Batzios S, Stathopoulos J, et al. Treatment of colorectal cancer with and without bevacizumab: a phase III study. Oncology [Internet]. 2010;78(5-6):376-81. Available from: http://dx.doi. org/10.1159/000320520.

95. Passardi A, Nanni O, Tassinari D, Turci D, Cavanna L, Fontana A, et al. Effectiveness of bevacizumab added to standard chemotherapy in metastatic colorectal cancer: final results for first-line treatment from the ITACa randomized clinical trial. Ann Oncol [Internet]. $2015 ; 26(6): 1201-7$. Available from: http://dx.doi. org/10.1093/annonc/mdv130.

96. Hochster HS, Hart LL, Ramanathan RK, Childs BH, Hainsworth JD, Cohn AL, et al. Safety and efficacy of oxaliplatin and fluoropyrimidine regimens with or without bevacizumab as first-line treatment of metastatic colorectal cancer: results of the TREE Study. J Clin Oncol [Internet]. 2008;26(21):3523-9. Available from: http://dx.doi.org/10.1200/JCO.2007.15.4138.

97. Giantonio BJ, Catalano PJ, Meropol NJ, O'Dwyer PJ, Mitchell EP, Alberts SR, et al. Bevacizumab in combination with 
oxaliplatin, fluorouracil, and leucovorin (FOLFOX4) for previously treated metastatic colorectal cancer: results from the Eastern Cooperative Oncology Group Study E3200. J Clin Oncol [Internet]. 2007;25(12):1539-44. Available from: http://dx.doi. org/10.1200/jco.2006.09.6305.

98. Saltz LB, Clarke S, Díaz-Rubio E, Scheithauer W, Figer A, Wong $\mathrm{R}$, et al. Bevacizumab in combination with oxaliplatinbased chemotherapy as first-line therapy in metastatic colorectal cancer: a randomized phase III study. J Clin Oncol [Internet]. 2008;26(12):2013-9. Available from: http://dx.doi.org/10.1200/ JCO.2007.14.9930

99. Vincenzi B, Santini D, Russo A, Spoto C, Venditti O, Gasparro $\mathrm{S}$, et al. Bevacizumab in association with de Gramont 5-fluorouracil/folinic acid in patients with oxaliplatin-, irinotecan-, and cetuximab-refractory colorectal cancer. Cancer [Internet]. 2009;115(20):4849-56. Available from: http://dx.doi. org/10.1002/cncr.24540.

100. Hurwitz HI, Tebbutt NC, Kabbinavar F, Giantonio BJ, Guan Z-Z, Mitchell L, et al. Efficacy and safety of bevacizumab in metastatic colorectal cancer: pooled analysis from seven randomized controlled trials. Oncologist [Internet]. 2013;18(9):1004-12. Available from: http://dx.doi.org/10.1634/theoncologist.2013-0107.

101. Heinemann V, von Weikersthal LF, Decker T, Kiani A, Vehling-Kaiser U, Al-Batran S-E, et al. FOLFIRI plus cetuximab versus FOLFIRI plus bevacizumab as first-line treatment for patients with metastatic colorectal cancer (FIRE-3): a randomised, open-label, phase 3 trial. Lancet Oncol [Internet]. 2014;15(10):1065-75. Available from: http://dx.doi.org/10.1016/ S1470-2045(14)70330-4.
102. Weeks JC, Catalano PJ, Cronin A, Finkelman MD, Mack JW, Keating NL, et al. Patients' expectations about effects of chemotherapy for advanced cancer. N Engl J Med [Internet]. 2012;367(17):1616-25. Available from: http://dx.doi org/10.1056/NEJMoa1204410.

103. New 50 million pound cancer fund already intellectually bankrupt. Lancet. 2010;376(9739):389.

104. Thompson DF. Understanding financial conflicts of interest. N Engl J Med. 1993;329:573-6.

105. Silva TBC, Almeida PHRF, Araújo VE, Acurcio FA, Guerra Júnior AA, Godman B, et al. Effectiveness and safety of insulin glargine versus detemir analysis in patients with type 1 diabetes: systematic review and meta-analysis. Ther Adv Endocrinol Metab. 2018;9(8):241-54.

106. Davis C, Abraham J. Is there a cure for corporate crime in the drug industry? BMJ. 2013;346:f755.

107. Civaner M. Sale strategies of pharmaceutical companies in a "pharmerging" country: the problems will not improve if the gaps remain. Health Policy. 2012;106:225-32.

108. Cohen D. Dabigatran: how the drug company withheld important analyses. BMJ. 2014;349:g467.

109. Lundh A, Lexchin J, Mintzes B, Schroll JB, Bero L. Industry sponsorship and research outcome: systematic review with metaanalysis. Intensive Care Med. 2018;44:1603-12.

110. Hakoum MB, Anouti S, Al-Gibbawi M, Abou-Jaoude EA, Hasbani DJ, Lopes LC, Agarwal A, Guyatt G, Akl EA. Reporting of financial and non-financial conflicts of interest by authors of systematic reviews: a methodological survey. BMJ Open. 2016;6:e 011997.

\section{Affiliations}

\section{Wânia Cristina da Silva ${ }^{1}\left(10\right.$ - Vânia Eloisa de Araujo ${ }^{1,2}\left(\right.$ Ellias Magalhães e Abreu Lima $^{3}$. Jessica Barreto Ribeiro dos Santos ${ }^{1}\left[\right.$ ] Michael Ruberson Ribeiro da Silva ${ }^{1} \mathbb{0}$.

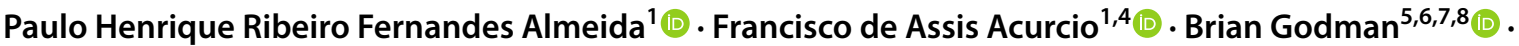 Amanj Kurdi ${ }^{5,9}$ - Mariângela Leal Cherchiglia ${ }^{1,4} \oplus$ Eli lola Gurgel Andrade ${ }^{1,4} \mathbb{D}$}

Wânia Cristina da Silva

wania_logistica@hotmail.com

Vânia Eloisa de Araujo

vaniaearaujo@gmail.com

Ellias Magalhães e Abreu Lima

ellias_lima@hotmail.com

Jessica Barreto Ribeiro dos Santos

jessicabarreto2203@gmail.com

Michael Ruberson Ribeiro da Silva mruberson@gmail.com

Paulo Henrique Ribeiro Fernandes Almeida henriqueribeiro.farm@gmail.com

Francisco de Assis Acurcio

fracurcio@gmail.com

Amanj Kurdi

amanj.baker@strath.ac.uk

Mariângela Leal Cherchiglia

mcherchiglia@gmail.com

Eli Iola Gurgel Andrade

eliola51@gmail.com; iola@medicina.ufmg.br
1 Postgraduate Program in Medicines and Pharmaceutical Services, School of Pharmacy, Federal University of Minas Gerais, Belo Horizonte, Brazil

2 School of Dentistry, Pontifical Catholic University of Minas Gerais, Belo Horizonte, Brazil

3 Mario Penna Institut of Oncology-Minas Gerais, Belo Horizonte, Brazil

4 Postgraduate Program in Public Health, School of Medicine, Federal University of Minas Gerais (UFMG), Belo Horizonte, Brazil

5 Strathclyde Institute of Pharmacy and Biomedical Sciences, University of Strathclyde, Glasgow, UK

6 Division of Clinical Pharmacology, Department of Laboratory Medicine, Karolinska Institutet, Karolinska University Hospital Huddinge, Stockholm, Sweden

7 Health Economics Centre, University of Liverpool Management School, Liverpool, UK

8 School of Pharmacy, Sefako Makgatho Health Sciences University, Garankuwa, Pretoria, South Africa

9 Department of Pharmacology, College of Pharmacy, Hawler Medical University, Erbil, Iraq 